\title{
Design Strategy for Robust Organic Semiconductor Laser Dyes
}

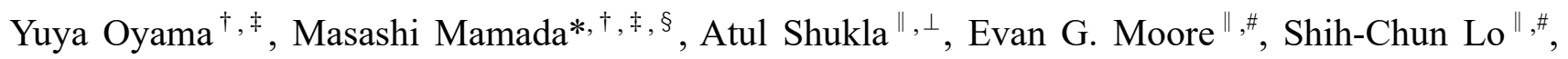
Ebinazar B. Namdas ${ }^{\|, \perp}$, Chihaya Adachi $*, \dagger, \ddagger, \S, \nabla$

${ }^{\dagger}$ Center for Organic Photonics and Electronics Research (OPERA), Kyushu University, Fukuoka 819-0395, Japan

${ }_{2}$ JST, ERATO, Adachi Molecular Exciton Engineering Project clo Center for Organic Photonics and Electronics Research (OPERA), Kyushu University, Nishi, Fukuoka 819-0395, Japan

$\S$ Academia-Industry Molecular Systems for Devices Research and Education Center (AIMS), Kyushu University, Nishi, Fukuoka 819-0395, Japan

" Centre for Organic Photonics \& Electronics, The University of Queensland, Brisbane, Queensland 4072, Australia

${ }^{\perp}$ School of Chemistry and Molecular Biosciences, The University of Queensland, Brisbane, Queensland 4072, Australia

${ }^{\#}$ School of Mathematics and Physics, The University of Queensland, Brisbane, Queensland 4072, Australia

${ }^{\nabla}$ International Institute for Carbon Neutral Energy Research (WPI-I2CNER), Kyushu University, Nishi, Fukuoka 819-0395, Japan

mamada@opera.kyushu-u.ac.jp (M.M.)

adachi@cstf.kyushu-u.ac.jp (C.A.) 


\section{Contents:}

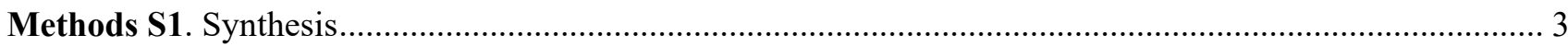

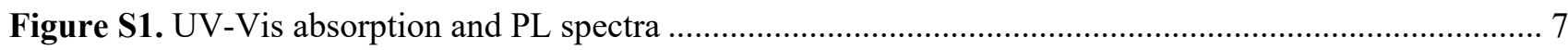

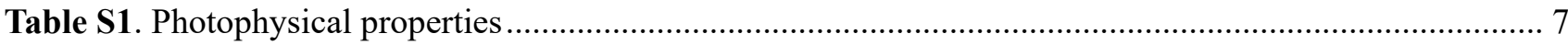

Figure S2. Cyclic voltammograms (CV) and differential pulse voltamograms (DPV).............................. 8

Figure S3. Photoelectron yield spectroscopy measurements ....................................................................... 8

Table S2. Redox potentials and HOMO-LUMO levels ............................................................................ 9

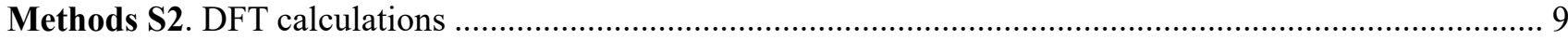

Table S3. Calculated HOMO-LUMO and first vertical singlet excitation energies (VEE) .............................. 9

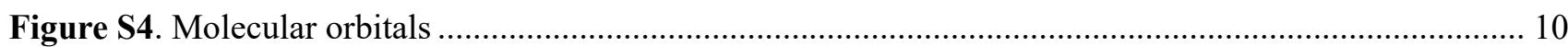

Figure S5. Out-of-plane X-ray diffractograms of neat films .....................................................................11

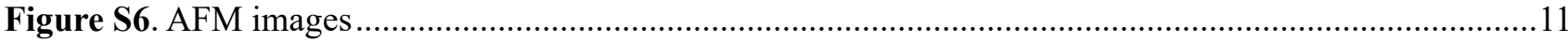

Figure S7. Variable-angle spectroscopic ellipsometry measurements of neat films ..................................... 12

Table S4. Ordinary and extraordinary refractive indices and orientation order parameters ........................... 12

Figure S8. Excited-state absorption spectra of BSBCz in toluene................................................................ 13

Figure S9. Excited-state absorption spectra of BPBFCz1 in toluene ........................................................ 14

Figure S10. Excited-state absorption spectra of BPBFCz2 in toluene ....................................................... 15

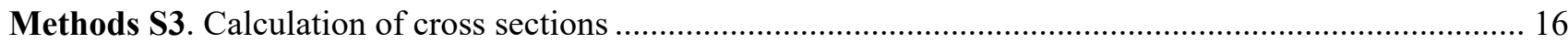

Figure S11. Absorption, stimulated emission, and triplet excited-states absorption cross sections ................ 16

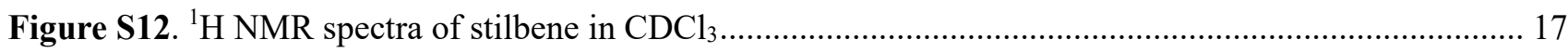

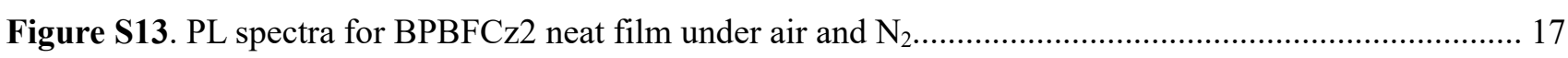

Figure S14. ASE intensity normalized to the initial for BSBCz, BPBFCz1, and BPBFCz2 neat films.......... 18

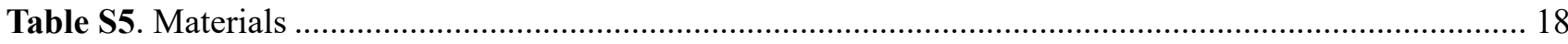

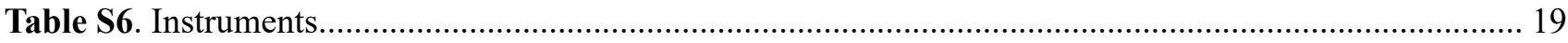

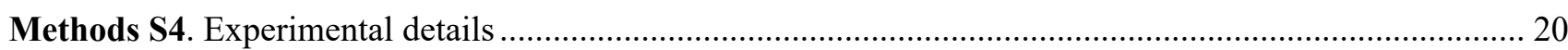

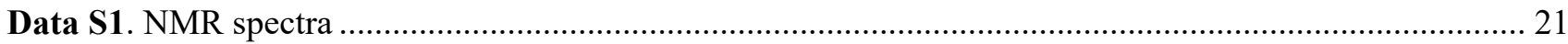

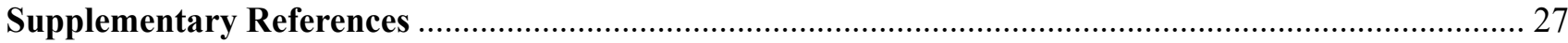


Methods S1. Synthesis

Compounds 1, 2, 7, and 10 were purchased. Compounds 3 and $\mathbf{4}$ were synthesized according to the literature. ${ }^{[\mathbf{S 1}, \mathbf{S 2}]}$ Commercially available materials were used as received from the suppliers for the synthesis.

$\underline{\text { Synthesis scheme }}$

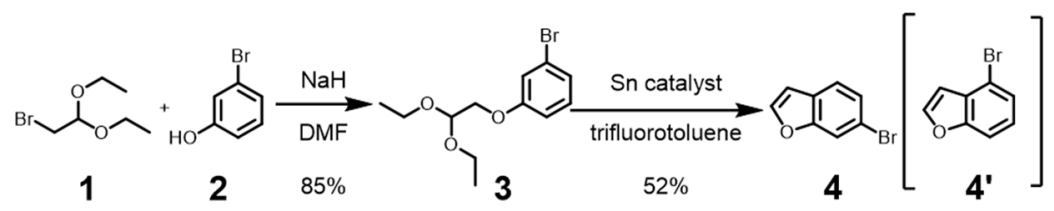

Scheme 1 (BPBFCz1)

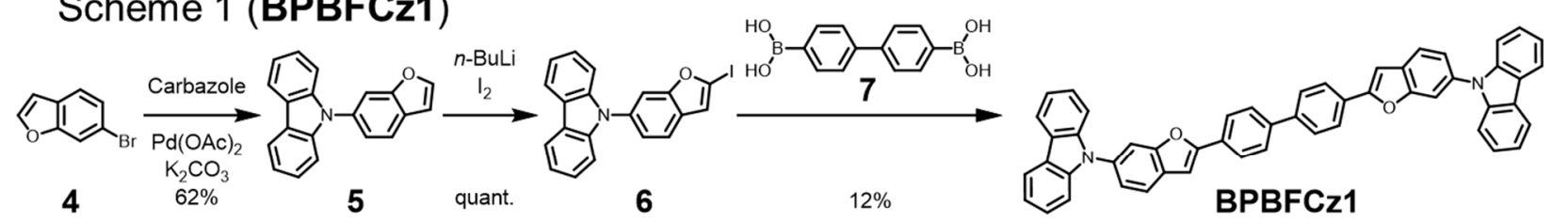

Scheme 2 (BPBFCz2)

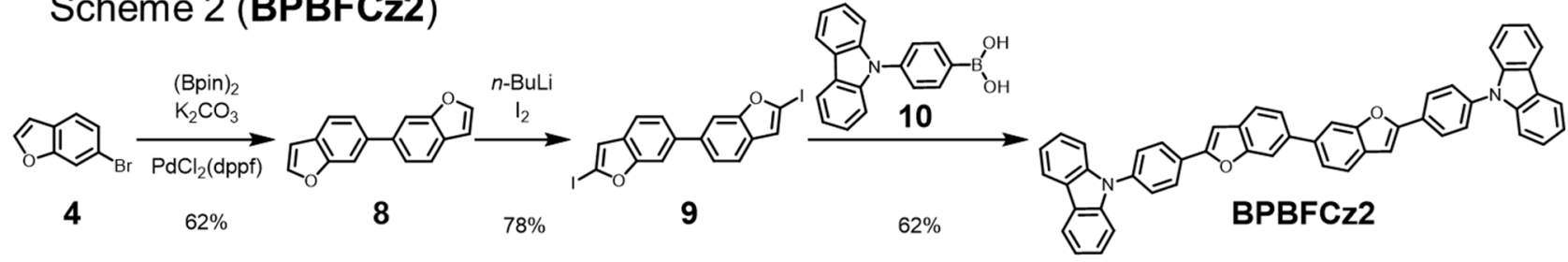

Compound 3<smiles>CCOC(COc1cccc(Br)c1)OCC</smiles>

$\mathrm{NaH}(12.8 \mathrm{~g}, 320 \mathrm{mmol})$ was added to a cold $0{ }^{\circ} \mathrm{C}$ solution of compound $2(30.0 \mathrm{~g}, 174 \mathrm{mmol})$ in DMF (200 mL) under argon. Compound 1 (31.5 g, $209 \mathrm{mmol})$ was slowly added dropwise, and the mixture was heated at $150{ }^{\circ} \mathrm{C}$ for $5 \mathrm{~h}$. After completion of the reaction, water was added at room temperature and the mixture was extracted with diethyl ether, dried over $\mathrm{Na}_{2} \mathrm{SO}_{4}$ and filtered. The filtrate was collected, and the solvent was removed. The crude product was purified by column chromatography over silica using DCM/hexane $(1: 1)$ as eluent $\left(R_{\mathrm{f}}=0.60\right)$ to give 3 as a colorless liquid (43 g, 85\%). ${ }^{1} \mathrm{H}$ NMR (500 MHz, $\left.\mathrm{CDCl}_{3}\right): \delta 7.07-7.15(\mathrm{~m}, 3 \mathrm{H}), 6.84-6.88(\mathrm{~m}, 1 \mathrm{H}), 4.81(\mathrm{t}, J=5.0$ $\mathrm{Hz}, 1 \mathrm{H}), 3.98-4.00(\mathrm{~d}, J=5.0 \mathrm{~Hz}, 2 \mathrm{H}), 3.72-3.79(\mathrm{~m}, 2 \mathrm{H}), 3.59-3.63(\mathrm{~m}, 2 \mathrm{H}), 1.25(\mathrm{t}, J=7.1 \mathrm{~Hz}, 6 \mathrm{H})$.

\section{Synthesis of Sn catalyst ( $\beta-\mathrm{Sn})$}

$\mathrm{H}-\beta$ zeolite $\left(\mathrm{SiO}_{2}: \mathrm{Al}_{2} \mathrm{O}_{3}=25: 10.1 \mathrm{~g}\right)$ was slowly added to $\mathrm{SnCl}_{2} \cdot 2 \mathrm{H}_{2} \mathrm{O}(2.34 \mathrm{~g}, 10.3 \mathrm{mmol})$ in ion exchange water $(450 \mathrm{~mL})$. The mixture was stirred for $24 \mathrm{~h}$ at room temperature and then filtered. The precipitated solid was washed with hot $50{ }^{\circ} \mathrm{C}$ ion exchange water until chloride ions were removed. The obtained solid was dried at $80{ }^{\circ} \mathrm{C}$ for $2 \mathrm{~h}$, and then calcined at $550^{\circ} \mathrm{C}$ for $5 \mathrm{~h}$ to give $\beta$-Sn $(9.45 \mathrm{~g})$. Note that the reaction sometimes failed, probably due to the quality of $\mathrm{H}-\beta$ zeolite. $\mathrm{H}-\beta$ zeolite purchased from Toso (HSZ-980HA) successfully gave the product. 


\section{Compound 4}

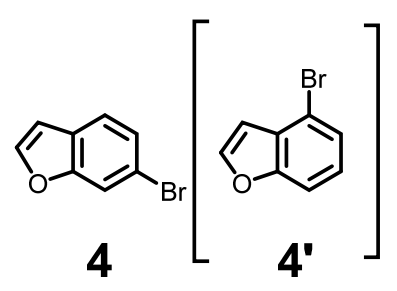

Compound 3 in benzenetrifluoride $(200 \mathrm{~mL})$ was added to $\beta$-Sn $(4.16 \mathrm{~g})$ under argon. The mixture was stirred at $110{ }^{\circ} \mathrm{C}$ for $72 \mathrm{~h}$. The mixture was filtered and washed with benzenetrifluoride $(10 \mathrm{~mL} \times 3)$ to remove the catalyst, and the filtrate was evaporated. The crude product was purified by column chromatography over silica using hexane as eluent $\left(R_{\mathrm{f}}=0.58\right)$ to give $\mathbf{4}$ and $\mathbf{4}^{\prime}$ as a colorless liquid $(\mathbf{4}, 49 \% ; \mathbf{4}, 3 \%) .{ }^{1} \mathrm{H}$ NMR $\left(500 \mathrm{MHz}, \mathrm{CDCl}_{3}\right): \delta 7.71(\mathrm{~s}$, $1 \mathrm{H}), 7.62(\mathrm{~d}, J=2.7 \mathrm{~Hz}, 1 \mathrm{H}), 7.49(\mathrm{~d}, J=9.6 \mathrm{~Hz}, 1 \mathrm{H}), 7.38(\mathrm{~d}, J=2.7 \mathrm{~Hz}, 1 \mathrm{H}), 6.76(\mathrm{~d}, J=2.7 \mathrm{~Hz})$.

\section{Compound 5}

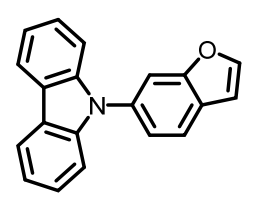

5

Compound 4 and 4' (4.11 g, $20.9 \mathrm{mmol})$, carbazole $(5.12 \mathrm{~g}, 30.6 \mathrm{mmol})$, palladium acetate $(160 \mathrm{mg}, 0.713 \mathrm{mmol})$ and potassium carbonate $(3.58 \mathrm{~g}, 25.9 \mathrm{mmol})$ were placed in a three necked flask and purged with argon, followed by addition of toluene $(150 \mathrm{~mL})$ and $\mathrm{P}^{t} \mathrm{Bu}_{3}(732 \mathrm{mg}, 3.62 \mathrm{mmol})$. The reaction mixture was heated at reflux under argon for 48 hours. After cooling to room temperature, the reaction mixture was quenched with water, extracted with ethyl acetate, dried over anhydrous $\mathrm{Na}_{2} \mathrm{SO}_{4}$, and filtered. The filtrate was collected and the solvent was removed. The crude product was purified by column chromatography over silica using DCM/hexane $(1: 1)$ as eluent $\left(R_{\mathrm{f}}=0.7\right)$ to give 5 as a colorless solid (3.66 g, 62\%). ${ }^{1} \mathrm{H}$ NMR (500 MHz, $\left.\mathrm{CDCl}_{3}\right): \delta 8.16(\mathrm{~d}, J=7.9 \mathrm{~Hz}, 2 \mathrm{H}), 7.79(\mathrm{~d}, J=8.2$ $\mathrm{Hz}, 1 \mathrm{H}), 7.76(\mathrm{~d}, J=2.2 \mathrm{~Hz}, 1 \mathrm{H}), 7.72(\mathrm{~s}, 1 \mathrm{H}), 7.45(\mathrm{dd}, J=8.2,1.9 \mathrm{~Hz}, 1 \mathrm{H}), 7.40-7.43(\mathrm{~m}, 4 \mathrm{H}), 7.28-7.32(\mathrm{~m}, 2 \mathrm{H})$, $6.91(\mathrm{dd}, J=2.2 \mathrm{~Hz}, 1 \mathrm{H}) ;{ }^{13} \mathrm{C} \mathrm{NMR}\left(125 \mathrm{MHz}, \mathrm{CDCl}_{3}\right): \delta 155.3,146.3,141.3,134.2,126.9,125.9,123.3,122.4$, 122.0, 120.3, 120.0, 110.6, 109.8, 106.7. Anal. calcd for $\mathrm{C}_{20} \mathrm{H}_{13} \mathrm{NO}$ : C 84.78, H 4.62, N 4.94; found: C 84.65, H 4.61, N 4.83 .

\section{Compound 6}

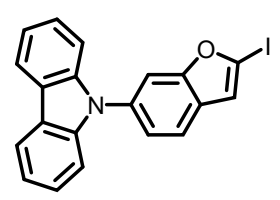

6

$n$-Buthyllithium ( $n$-BuLi, $1.6 \mathrm{M}, 1.64 \mathrm{~mL}, 2.63 \mathrm{mmol})$ was added to a cold $-40{ }^{\circ} \mathrm{C}$ solution of $5(0.496 \mathrm{~g}, 1.75$ $\mathrm{mmol})$ in THF $(10 \mathrm{~mL})$ under argon. The mixture was stirred at $-40{ }^{\circ} \mathrm{C}$ for $1 \mathrm{~h}$, followed by addition of a solution of $\mathrm{I}_{2}(0.724 \mathrm{~g}, 2.85 \mathrm{mmol})$ in THF $(10 \mathrm{~mL})$. After 10 minutes, the mixture was warmed to room temperature and then 
stirred overnight. Saturated aqueous $\mathrm{Na}_{2} \mathrm{~S}_{2} \mathrm{O}_{3}(20 \mathrm{~mL})$ was added to the mixture, and THF was removed under reduced pressure. The mixture was extracted with ethyl acetate $(2 \times 50 \mathrm{~mL} \mathrm{~mL})$, dried over $\mathrm{Na}_{2} \mathrm{SO}_{4}$, and filtered. The filtrate was collected and the solvent was removed. The crude product was purified by column chromatography over silica using DCM as eluent $\left(R_{\mathrm{f}}=0.8\right)$ to give 6 as a colorless solid, $(0.734 \mathrm{~g}, 100 \%)$. mp 80.2-81.9 ${ }^{\circ} \mathrm{C},{ }^{1} \mathrm{H}$ NMR $(500$ $\left.\mathrm{MHz}, \mathrm{CDCl}_{3}\right): \delta 8.17(\mathrm{t}, J=1.0,1 \mathrm{H}), 8.15(\mathrm{~s}, 1 \mathrm{H}) 7.71(\mathrm{~s}, 1 \mathrm{H}) 7.69-7.70(\mathrm{~m}, 2 \mathrm{H}), 7.39-7.45(\mathrm{~m}, 4 \mathrm{H}), 7.28-7.32(\mathrm{~m}$, 2H), $\left.7.09(\mathrm{~d}, J=1.0 \mathrm{~Hz}, 1 \mathrm{H}) ;{ }^{13} \mathrm{C} \mathrm{NMR}\left(125 \mathrm{MHz}, \mathrm{CDCl}_{3}\right): \delta\right)$ 158.4, 141.1, 134.2, 128.6, 126.0, 123.4, 122.7, 120.4, 120.3, 120.1, 117.3, 110.0, 110.0, 97.1. Anal. calcd for $\mathrm{C}_{20} \mathrm{H}_{12} \mathrm{INO}$ : C 58.70, H 2.96, N 3.42; found: C 58.47, H 2.99, N 3.25 .

\section{Compound 8}

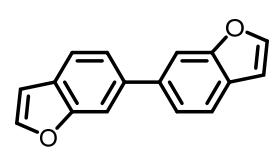

8

Compound 4 (1.03 g, $5.26 \mathrm{mmol})$, bis(pinacolato)diboron [(BPin) $2,645 \mathrm{mg}, 2.54 \mathrm{mmol}$ ], [bis (diphenylphosphino)ferrocene]palladium(II)dichloride [ $\mathrm{PdCl}_{2}$ (dppf), $150 \mathrm{mg}, 0.205 \mathrm{mmol}$ ], and $\mathrm{K}_{2} \mathrm{CO}_{3}(2.13 \mathrm{~g}, 15.4$ $\mathrm{mmol}$ ) were placed in a two-necked flask and purged with argon. Dimethyl sulfoxide (DMSO, $30 \mathrm{~mL}$ ) was added to the mixture and heated at $80^{\circ} \mathrm{C}$ under argon for $24 \mathrm{~h}$. After cooling to room temperature, water was added to the mixture, and the precipitate formed was filtered. The crude product was purified by column chromatography over silica using DCM/hexane (1:9) as eluent $\left(R_{\mathrm{f}}=0.4\right)$ to give 8 as a colorless solid $(0.379 \mathrm{~g}, 62 \%) . \mathrm{mp} 103.6-104.8^{\circ} \mathrm{C}$, ${ }^{1} \mathrm{H}$ NMR (500 MHz, CDCl $): \delta 7.77(\mathrm{~s}, 2 \mathrm{H}), 7.66-7.67(\mathrm{~m}, 4 \mathrm{H}), 7.53(\mathrm{dd}, J=8.0,1.5 \mathrm{~Hz}, 2 \mathrm{H}), 6.81(\mathrm{dd}, J=1.0 \mathrm{~Hz}$, $2 \mathrm{H}) ;{ }^{13} \mathrm{C}$ NMR $\left(125 \mathrm{MHz}, \mathrm{CDCl}_{3}\right): \delta 155.8,145.6,138.3,126.7,122.8,121.4,110.3$, 106.6. Anal. calcd for $\mathrm{C}_{16} \mathrm{H}_{10} \mathrm{O}_{2}$ : C 82.04, H 4.30; found: C 81.97, H, 4.46.

\section{Compound 9}

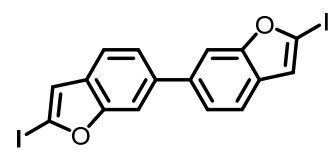

9

$n$-Buthyllithium (1.6 M, $2.80 \mathrm{~mL}, 4.34 \mathrm{mmol})$ was added to a cold $\left(-40^{\circ} \mathrm{C}\right)$ solution of $8(315 \mathrm{mg}, 1.35 \mathrm{mmol})$ in THF $(10 \mathrm{~mL})$ under argon. The mixture was stirred at $-40{ }^{\circ} \mathrm{C}$ for $1 \mathrm{~h}$, followed by addition of a solution of $\mathrm{I}_{2}(1.03$ $\mathrm{g}, 4.06 \mathrm{mmol})$ in THF $(10 \mathrm{~mL})$. After 10 minutes, the mixture was warmed to room temperature and then stirred overnight. Saturated aqueous $\mathrm{Na}_{2} \mathrm{~S}_{2} \mathrm{O}_{3}(20 \mathrm{~mL})$ was added to the mixture, and THF was removed under reduced pressure. The mixture was extracted with ethyl acetate $(2 \times 100 \mathrm{~mL})$, dried over $\mathrm{Na}_{2} \mathrm{SO}_{4}$, and filtered. The filtrate was collected and the solvent was removed. The crude product was purified by column chromatography on a silica gel using DCM as eluent $\left(R_{\mathrm{f}}=0.9\right)$ to give 9 as a colorless solid $(0.654 \mathrm{~g}, 78 \%)$. mp 372.4-374.1 ${ }^{\circ} \mathrm{C} .{ }^{1} \mathrm{H}$ NMR $(500$ $\left.\mathrm{MHz}, \mathrm{CDCl}_{3}\right): \delta 7.70(\mathrm{~s}, 2 \mathrm{H}), 7.57(\mathrm{~d}, J=8.0 \mathrm{~Hz}, 2 \mathrm{H}), 7.49(\mathrm{dd}, J=8.0,1.5 \mathrm{~Hz}, 2 \mathrm{H}), 6.99(\mathrm{~d}, J=1.0 \mathrm{~Hz}, 2 \mathrm{H}) ;{ }^{13} \mathrm{C}$ 
NMR (125 MHz, $\left.\mathrm{CDCl}_{3}\right): \delta 161.6,140.4,131.2,125.7,122.6,119.9,112.3,99.0$. Anal. calcd for $\mathrm{C}_{16} \mathrm{H}_{8} \mathrm{I}_{2} \mathrm{O}_{2}: \mathrm{C}_{3} 9.54$, H 1.66; found: C 39.85, H 1.62 .

\section{$\underline{\mathrm{BPBFCz} 1}$}

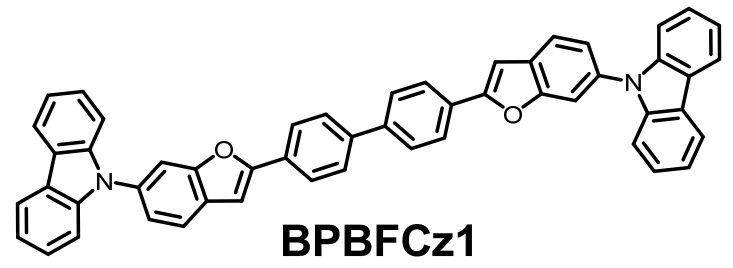

Compound 7 (169 mg, $0.698 \mathrm{mmol})$ and tetrakis(triphenylphosphine)palladium(0) $\left(\mathrm{Pd}\left(\mathrm{PPh}_{3}\right)_{4}, 226 \mathrm{mg}, 0.196\right.$ $\mathrm{mmol})$ were placed in a two-necked flask and purged with argon. A solution of 6 (730 mg, $1.78 \mathrm{mmol})$ in toluene (50 $\mathrm{mL}$ ) was added to the mixture, followed by addition of $\mathrm{K}_{2} \mathrm{CO}_{3}(436 \mathrm{mg}, 3.15 \mathrm{mmol})$ in water $(50 \mathrm{~mL})$. The reaction mixture was heated at reflux under argon for $48 \mathrm{~h}$. After cooling, the mixture was filtered and washed with DCM (20 $\mathrm{mL})$ and $\mathrm{KOH}$ aq $(1.8 \mathrm{M}, 50 \mathrm{~mL})$. The crude product was purified by column chromatography over silica using DCM/hexane (1:3) as eluent $\left(R_{\mathrm{f}}=0.2\right)$ to give BPBFCz1 as a yellow solid $(60.8 \mathrm{mg}, 12 \%)$. mp $358.8^{\circ} \mathrm{C} .{ }^{1} \mathrm{H} \mathrm{NMR}$ $\left(500 \mathrm{MHz}, \mathrm{CDCl}_{3}\right): \delta 8.18(\mathrm{~d}, J=7.6 \mathrm{~Hz}, 4 \mathrm{H}), 8.05(\mathrm{~d}, J=8.2 \mathrm{~Hz}, 4 \mathrm{H}), 7.84(\mathrm{~d}, J=7.9 \mathrm{~Hz}, 6 \mathrm{H}), 7.76(\mathrm{~s}, 2 \mathrm{H}), 7.41-$ $7.49(\mathrm{~m}, 10 \mathrm{H}) 7.30-7.31(\mathrm{t}, J=6.9 \mathrm{~Hz}, 4 \mathrm{H}), 7.28(\mathrm{~s}, 2 \mathrm{H}) ;{ }^{13} \mathrm{C} \mathrm{NMR}\left(125 \mathrm{MHz}, \mathrm{CDCl}_{3}\right): \delta 155.5,148.6,141.4,140.9$, 134.4, 130.6, 129.6, 127.6, 126.2, 125.7, 123.6, 122.7, 121.8, 120.5, 120.1, 110.5, 110.0, 101.7; Anal. calcd for $\mathrm{C}_{52} \mathrm{H}_{32} \mathrm{~N}_{2} \mathrm{O}_{2}:$ C 87.13, H 4.50, N 3.91; found: C 86.86, H 4.46, N 3.83 .

\section{$\underline{\mathrm{BPBFCz} 2}$}

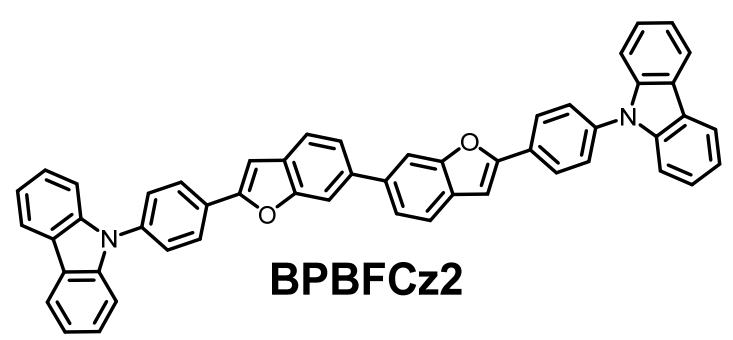

Compound 10 (1.06 g, $3.69 \mathrm{mmol})$ and tetrakis(triphenylphosphine)palladium(0) ( $\left.\mathrm{Pd}\left(\mathrm{PPh}_{3}\right)_{4}, 124 \mathrm{mg}, 0.107 \mathrm{mmol}\right)$ were placed in a two-necked flask and purged with argon. A solution of $9(510 \mathrm{mg}, 1.04 \mathrm{mmol})$ in toluene $(50 \mathrm{~mL})$ was added to the mixture, followed by addition of $\mathrm{K}_{2} \mathrm{CO}_{3}(1.20 \mathrm{~g}, 8.68 \mathrm{mmol})$ in water $(50 \mathrm{~mL})$. The reaction mixture was heated at reflux under argon for $36 \mathrm{~h}$. After cooling, the mixture was filtered and washed with DCM (30 mL) and aqueous $\mathrm{KOH}(1.8 \mathrm{M}, 50 \mathrm{~mL})$. The mixture was dissolved in $o$-dichlorobenzene $(30 \mathrm{~mL})$ at $180{ }^{\circ} \mathrm{C}$ and recrystallized with methanol to give BPBFCz2 as a yellow solid (464 mg, 62\%). mp 311.6 ${ }^{\circ} \mathrm{C} .{ }^{1} \mathrm{H} \mathrm{NMR}(500 \mathrm{MHz}$, $\left.\mathrm{CD}_{2} \mathrm{Cl}_{2}\right): \delta 8.17(\mathrm{~d}, J=8.8 \mathrm{~Hz}, 8 \mathrm{H}), 7.92(\mathrm{~s}, 2 \mathrm{H}), 7.71-7.77(\mathrm{~m}, 6 \mathrm{H}), 7.67(\mathrm{dd}, J=8.2,1.3 \mathrm{~Hz}, 2 \mathrm{H}), 7.52(\mathrm{~d}, J=8.2$ $\mathrm{Hz}, 4 \mathrm{H}), 7.46(\mathrm{t}, J=7.3,4 \mathrm{H}) 7.32(\mathrm{t}, J=6.9 \mathrm{~Hz}, 4 \mathrm{H}), 7.24(\mathrm{~s}, 2 \mathrm{H}) ;{ }^{13} \mathrm{C}$ NMR $\left(125 \mathrm{MHz}, \mathrm{CD}_{2} \mathrm{Cl}_{2}\right): \delta 155.8,140.6$, $138.2,137.8,129.3,128.5,127.3,126.3,126.0,123.5,122.9,121.3,120.3,120.1,109.8,109.6,101.9$. Anal. calcd for $\mathrm{C}_{52} \mathrm{H}_{32} \mathrm{~N}_{2} \mathrm{O}_{2}$ : C 87.13, H 4.50, N 3.91; found: C 86.99, H 4.51, N 3.67. 
(a)

(b)

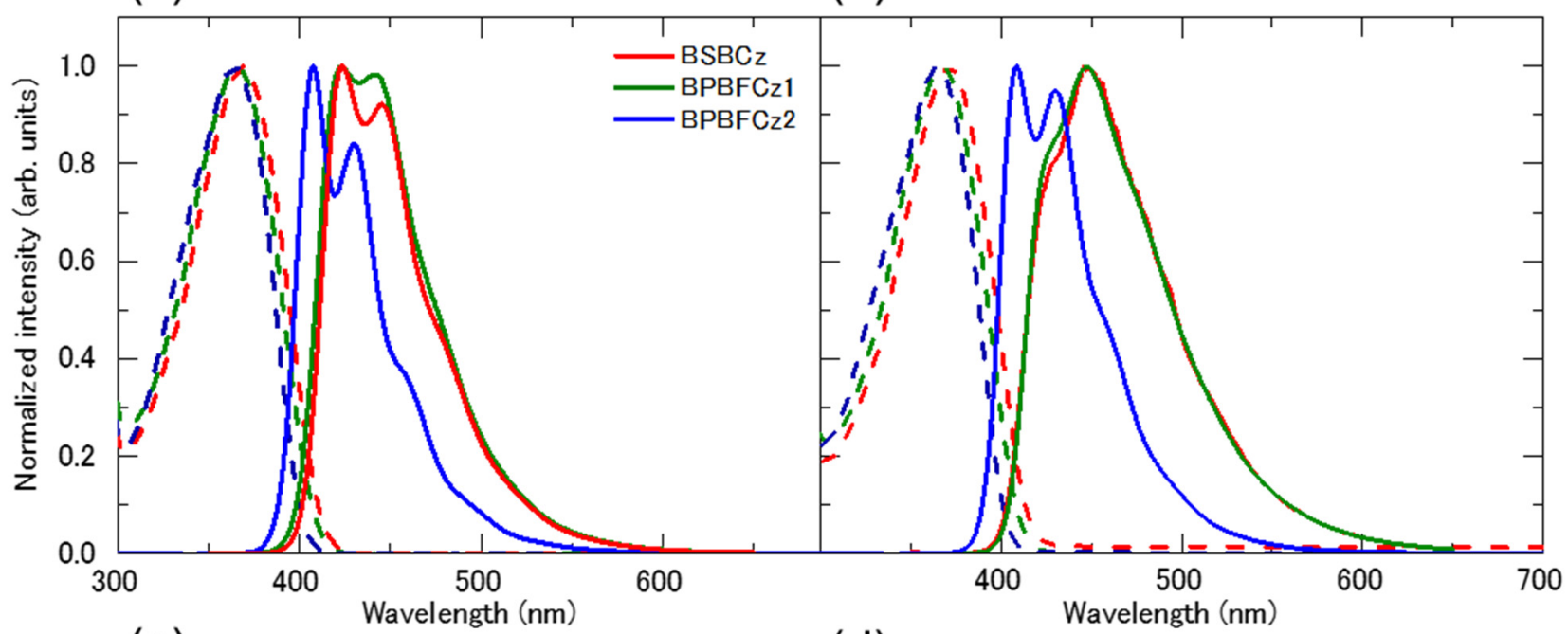

(c)

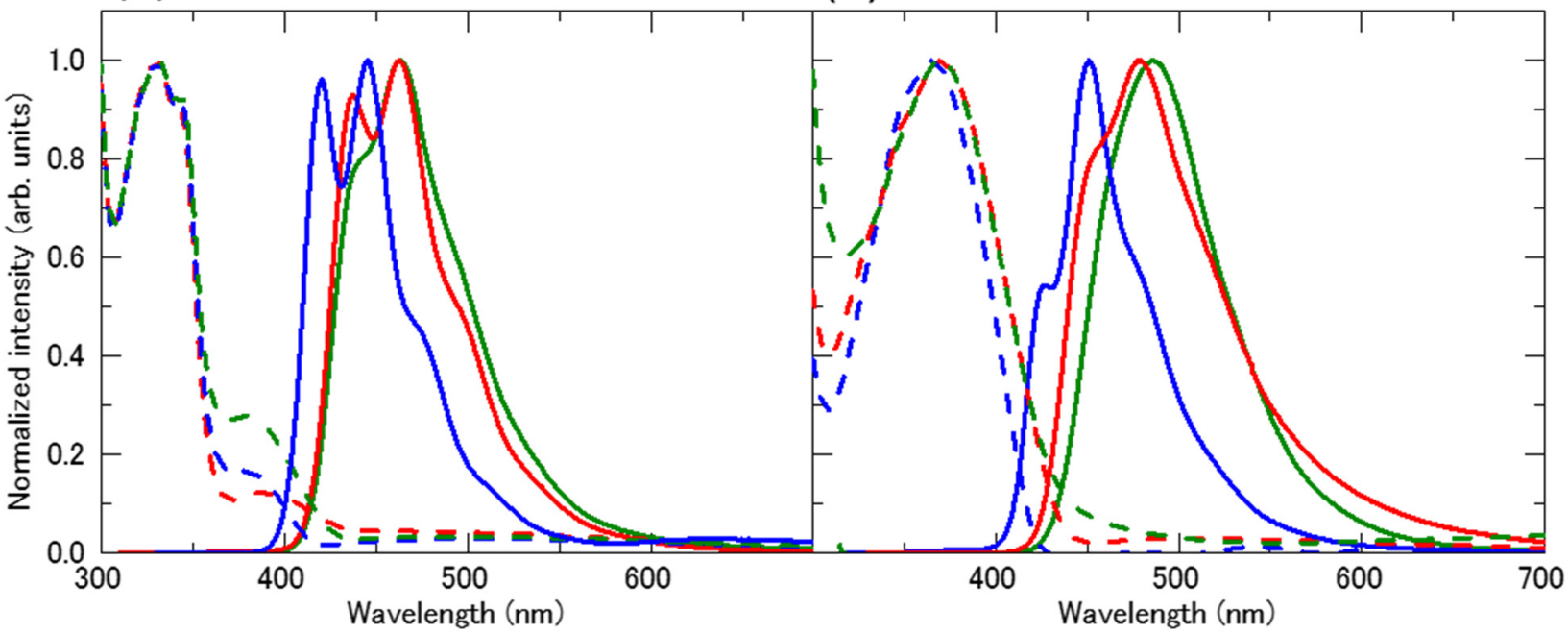

Figure S1. UV-Vis absorption and PL spectra for $\mathrm{BSBC}$, BPBFCz1, and BPBFCz2 in (a) chloroform, (b) DMF, (c) $6 \mathrm{wt} \%$ doped in CBP films and (d) neat films.

Table S1. Photophysical properties of BSBCz, BPBFCz1, and BPBFCz2 in chloroform and DMF

\begin{tabular}{ccccccc}
\hline Compd. & Condition & $\begin{array}{c}\lambda_{\mathrm{abs}} \\
{[\mathrm{nm}]}\end{array}$ & $\begin{array}{c}\lambda_{\mathrm{PL}} \\
{[\mathrm{nm}]}\end{array}$ & $\begin{array}{c}\Phi_{\mathrm{PL}} \\
{[-]^{\mathrm{a})}}\end{array}$ & $\begin{array}{c}\tau \\
{[\mathrm{ns}]^{\mathrm{b})}}\end{array}$ & $\begin{array}{c}k_{\mathrm{r}} / 10^{8} \\
{\left[\mathrm{~s}^{-1}\right]}\end{array}$ \\
\hline BSBCz & In CHCl & 369 & 423,446 & 0.88 & 0.95 & 9.3 \\
BSBCz & In DMF & 373 & 430,446 & 0.96 & 1.1 & 8.5 \\
BPBFCz1 & In CHCl $_{3}$ & 366 & 423,441 & 0.96 & 1.1 & 8.9 \\
BPBFCz1 & In DMF & 368 & 426,447 & 0.96 & 1.4 & 6.8 \\
BPBFCz2 & In CHCl & 365 & 407,430 & 0.96 & 0.99 & 9.7 \\
BPBFCz2 & In DMF & 365 & 409,430 & 1.00 & 1.04 & 9.6 \\
\hline
\end{tabular}

a) Absolute PL quantum yield evaluated using an integrating sphere in $\mathrm{N}_{2}$. ${ }^{\text {b) }}$ In $\mathrm{N}_{2}$. 
(a)

(b)

(c)

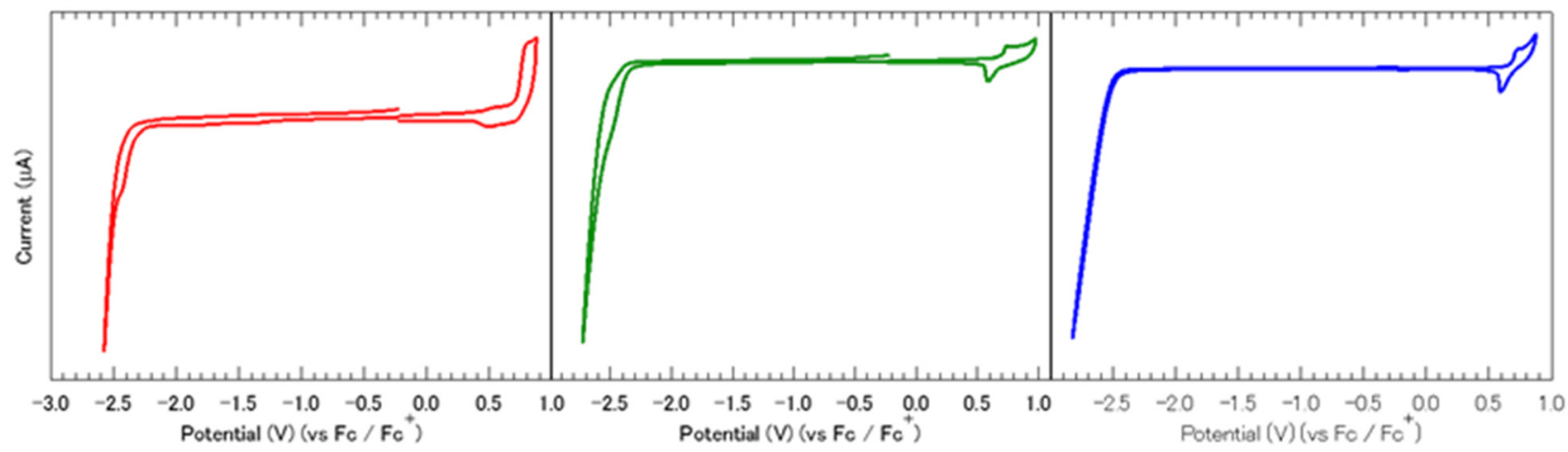

(d)

(e)

(f)

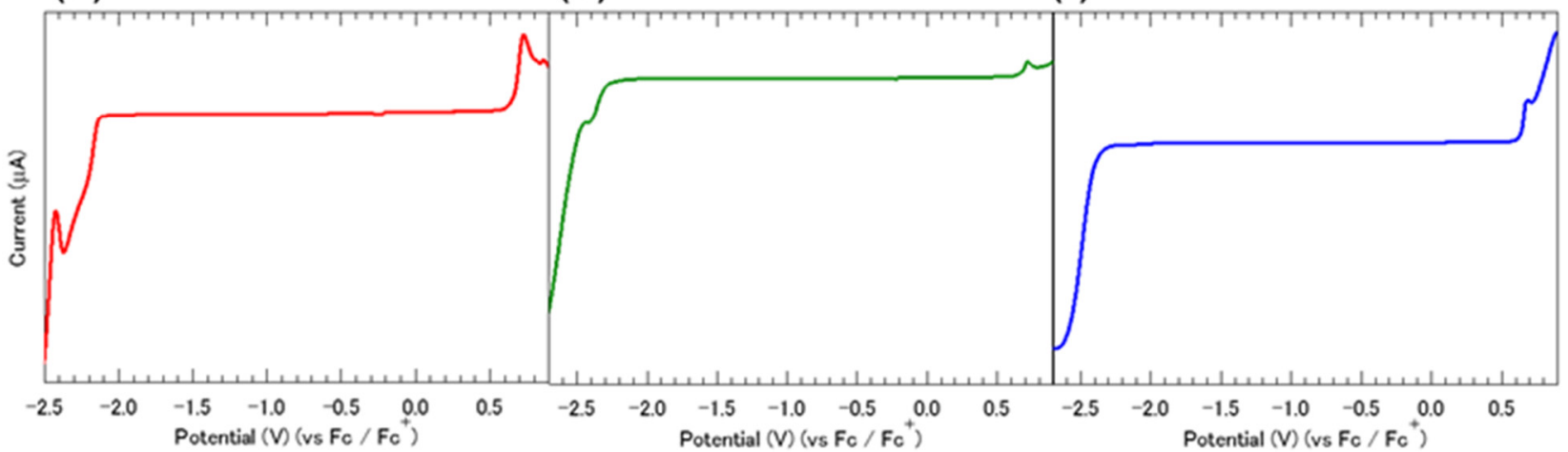

Figure S2. Cyclic voltammograms (CV) and differential pulse voltamograms (DPV). CV for (a) BSBCz, (b) BPBFCz1, and (c) BPBFCz2 and DPV for (d) BSBCz, (e)BPBFCz1, and (f) BPBFCz2 in dichloromethane (vs $\left.\mathrm{Fc} / \mathrm{Fc}^{+}\right)$.

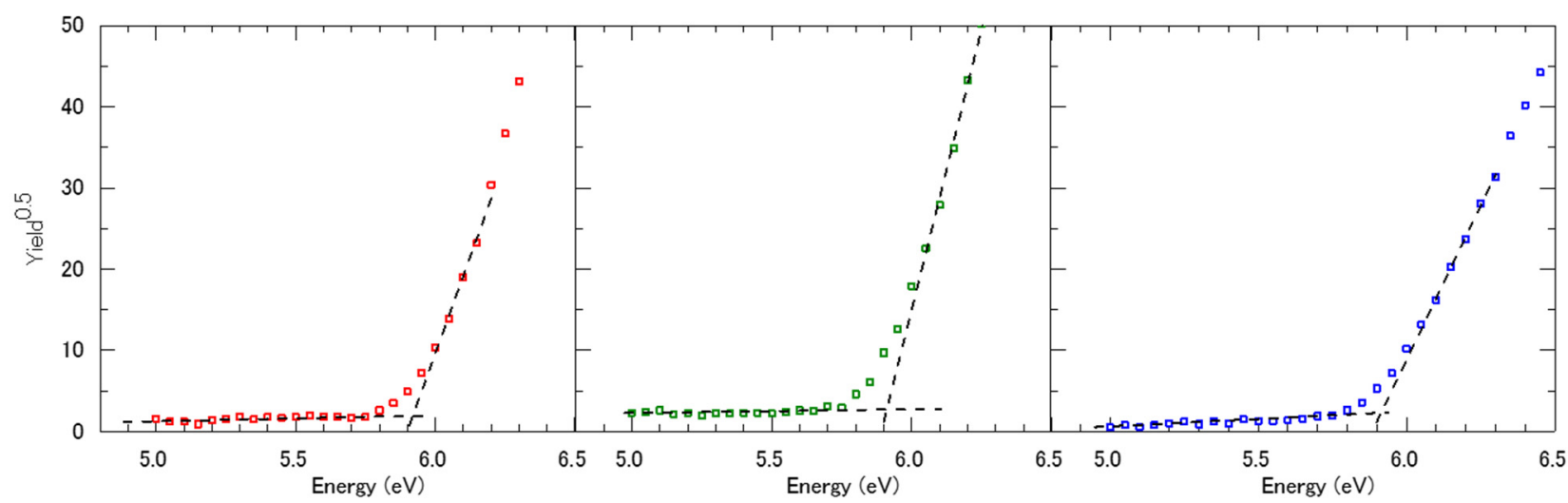

Figure S3. Photoelectron yield spectroscopy measurements for neat films of BSBCz, BPBFCz1, and BPBFCz2 recorded with a Riken Keiki AC-3. 
Table S2. Redox potentials and HOMO-LUMO levels of BSBCz, BPBFCz1, and BPBFCz2

\begin{tabular}{|c|c|c|c|c|c|c|c|c|}
\hline \multirow{2}{*}{ Compd. } & \multicolumn{2}{|c|}{$\mathrm{CV}$} & \multicolumn{2}{|c|}{ DPV } & \multirow{2}{*}{$\begin{array}{c}\text { HOMO } \\
(\mathrm{eV})\end{array}$} & \multirow{2}{*}{$\begin{array}{c}\text { LUMO } \\
(\mathrm{eV})\end{array}$} & \multirow{2}{*}{$\begin{array}{c}E_{\mathrm{g}}^{\text {redox }} \\
\text { (V) }\end{array}$} & \multirow{2}{*}{$\begin{array}{c}E_{\mathrm{g}}{ }^{\mathrm{opt}} \\
(\mathrm{V})\end{array}$} \\
\hline & $E_{\mathrm{ox}}(\mathrm{V})$ & $E_{\text {red }}(\mathrm{V})$ & $E_{\mathrm{ox}}(\mathrm{V})$ & $E_{\text {red }}(\mathrm{V})$ & & & & \\
\hline $\mathrm{BSBCz}$ & 0.743 & -2.39 & 0.732 & -2.36 & -5.53 & -2.44 & 3.09 & 2.93 \\
\hline BPBFCz1 & 0.666 & -2.42 & 0.692 & -2.40 & -5.49 & -2.40 & 3.09 & 2.93 \\
\hline BPBFCz2 & 0.657 & - & 0.684 & -2.64 & -5.48 & -2.16 & 3.32 & 3.05 \\
\hline
\end{tabular}

\section{Methods S2. DFT calculations}

Quantum chemical calculations were performed using the computer facilities at the Research Institute for Information Technology, Kyushu University. Molecular orbital calculations were performed using the program Gaussian 16. ${ }^{[\mathrm{S} 3]}$ The structures of the ground state were optimized at the B3LYP/6-31+G(d,p) level. It was confirmed that imaginary vibration is not included by the frequency calculation. The time-dependent density functional theory (TD-DFT) calculations were conducted at the B3LYP/6-31+G(d,p) level.

Table S3. Calculated HOMO-LUMO and first vertical singlet excitation energies (VEE) of BSBCz, BPBFCz1, and BPBFCz2

\begin{tabular}{|c|c|c|c|c|c|c|c|}
\hline Compd. & $\begin{array}{c}\mathrm{HOMO} \\
{[\mathrm{eV}]}\end{array}$ & $\begin{array}{l}\text { LUMO } \\
{[\mathrm{eV}]}\end{array}$ & $\begin{array}{l}\text { Gap } \\
{[\mathrm{eV}]}\end{array}$ & $\begin{array}{c}\mathrm{S}_{1-\text {-vertical }} \\
{[\mathrm{eV}]}\end{array}$ & VEE & $\begin{array}{c}\mathrm{S}_{1-\text { adiabatic }} \\
{[\mathrm{eV}]}\end{array}$ & VEE \\
\hline $\mathrm{BSBCz}$ & -5.47 & -2.30 & 3.17 & -57492.035 & $\begin{array}{c}2.82 \mathrm{eV} \\
439 \mathrm{~nm} \\
f=2.0066\end{array}$ & -57492.246 & $\begin{array}{c}2.41 \mathrm{eV} \\
514 \mathrm{~nm} \\
f=2.7561\end{array}$ \\
\hline BPBFCz1 & -5.52 & -2.24 & 3.28 & -61520.620 & $\begin{array}{c}2.92 \mathrm{eV} \\
424 \mathrm{~nm} \\
f=1.2596\end{array}$ & -61520.839 & $\begin{array}{c}2.51 \mathrm{eV} \\
495 \mathrm{~nm} \\
f=1.9995\end{array}$ \\
\hline BPBFCz2 & -5.48 & -2.04 & 3.44 & -61520.498 & $\begin{array}{c}3.04 \mathrm{eV} \\
408 \mathrm{~nm} \\
f=1.8440\end{array}$ & -61520.696 & $\begin{array}{c}2.65 \mathrm{eV} \\
468 \mathrm{~nm} \\
f=2.4852\end{array}$ \\
\hline
\end{tabular}




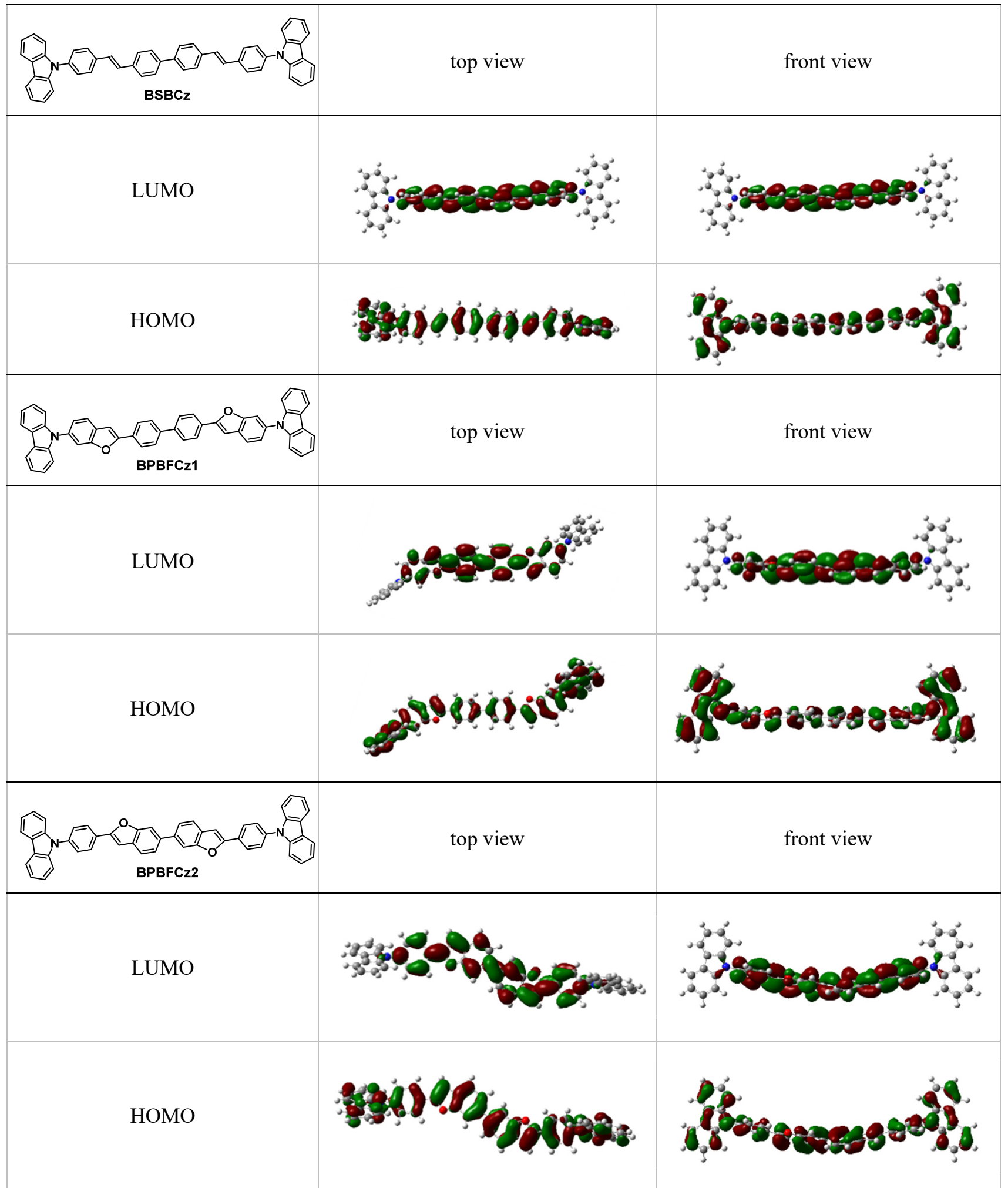

Figure S4. Molecular orbitals of BSBCz, BPBFCz1, and BPBFCz2 
(a)

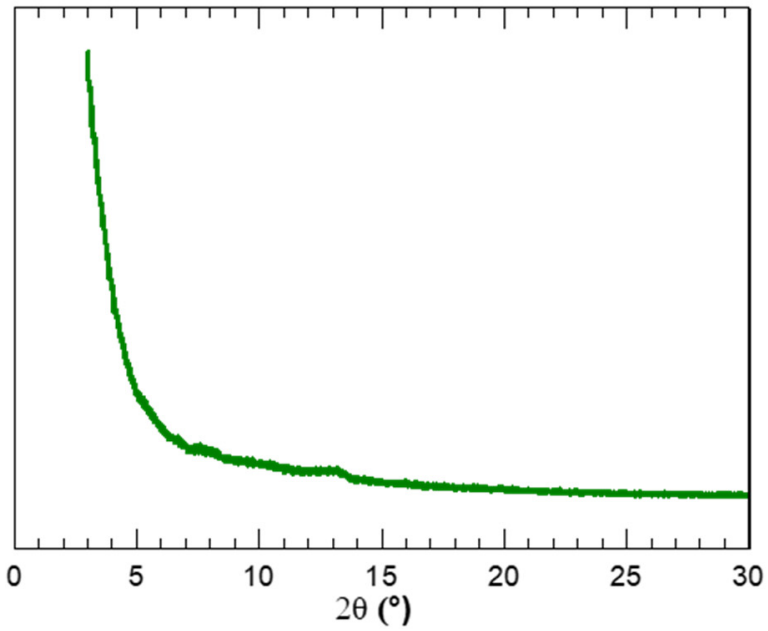

(b)

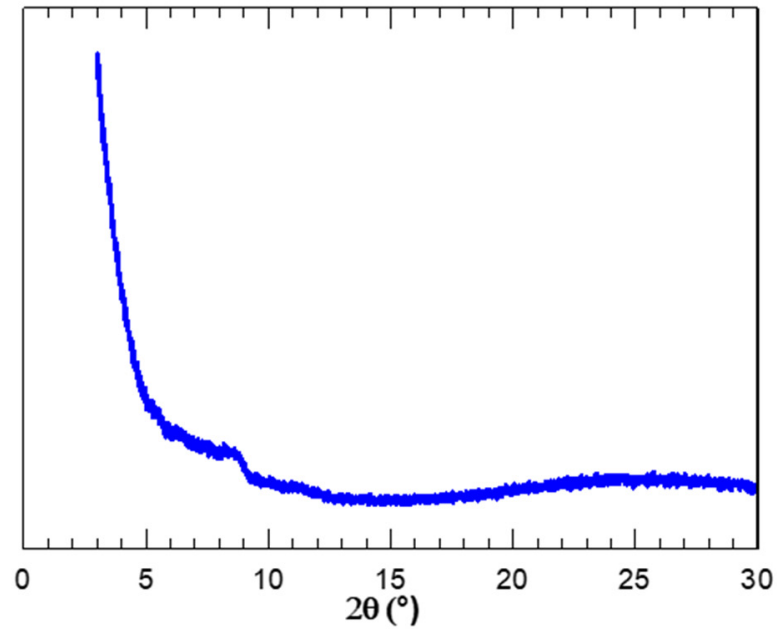

Figure S5. Out-of-plane X-ray diffractograms of neat films of (a) BPBFCz1 and (b) BPBFCz2.

(a)
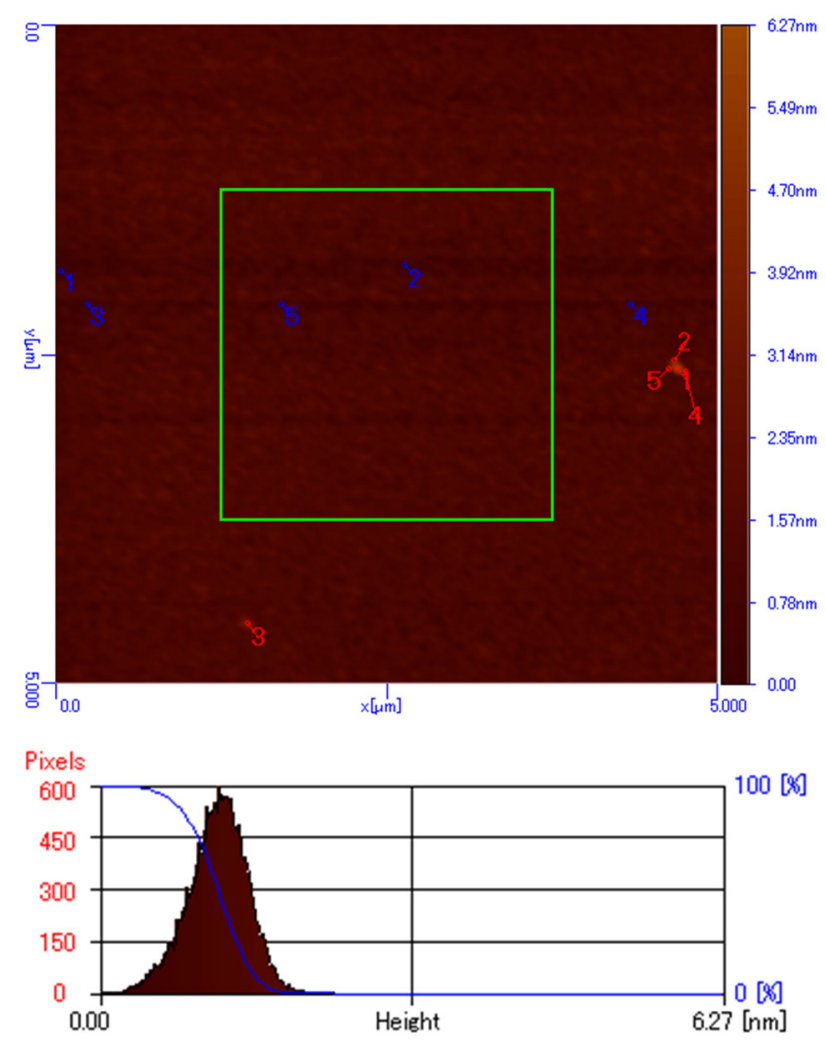

(b)
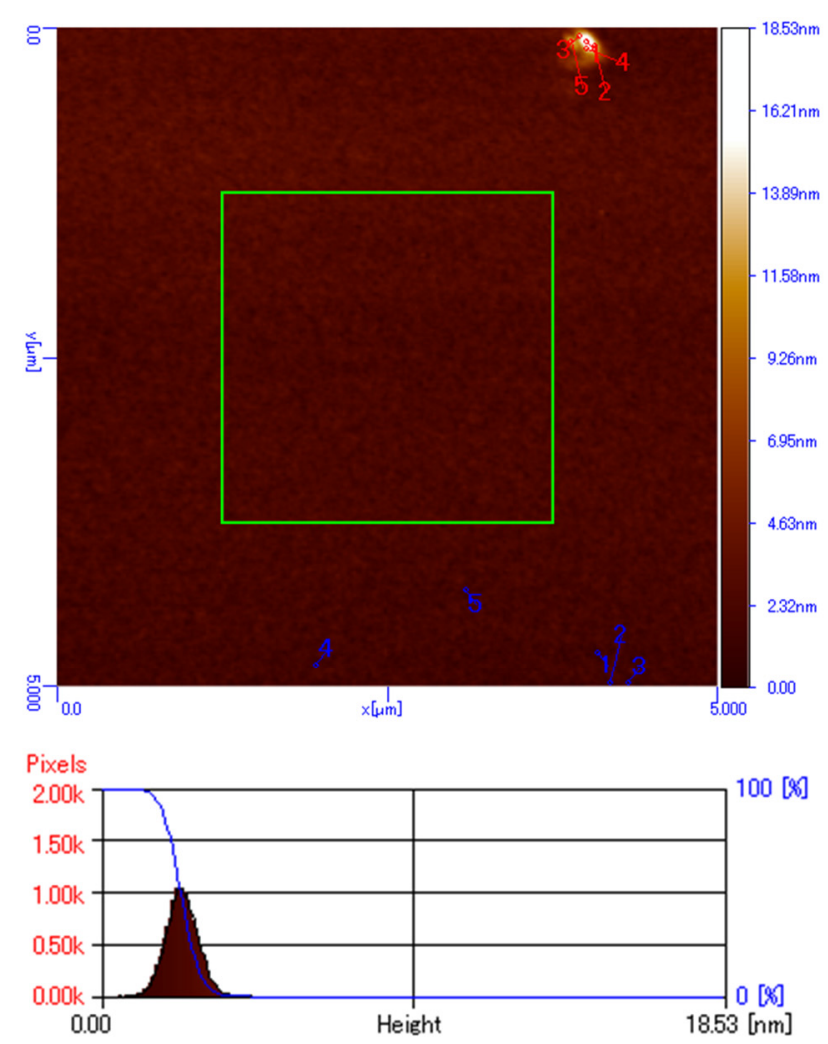

Figure S6. AFM images of (a) BPBFCz1 and (b) BPBFCz2. The values of root mean square (RMS) of the surface roughness of the films were $0.40,0.23$ and $0.36 \mathrm{~nm}$ for $\mathrm{BSBCz},{ }^{\mathrm{S} 4} \mathrm{BPBFCz} 1$ and BPBFCz2. 
(a)

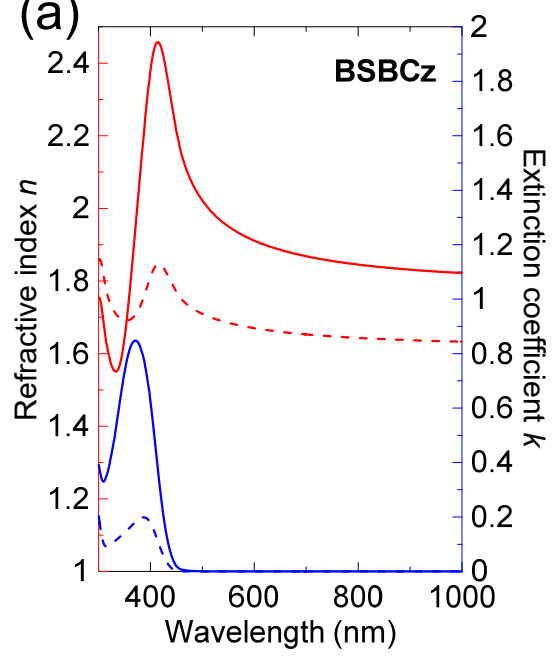

(b)

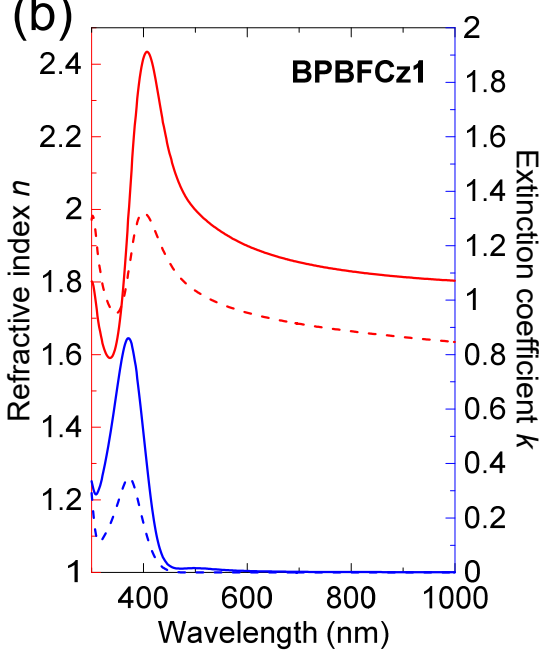

(c)

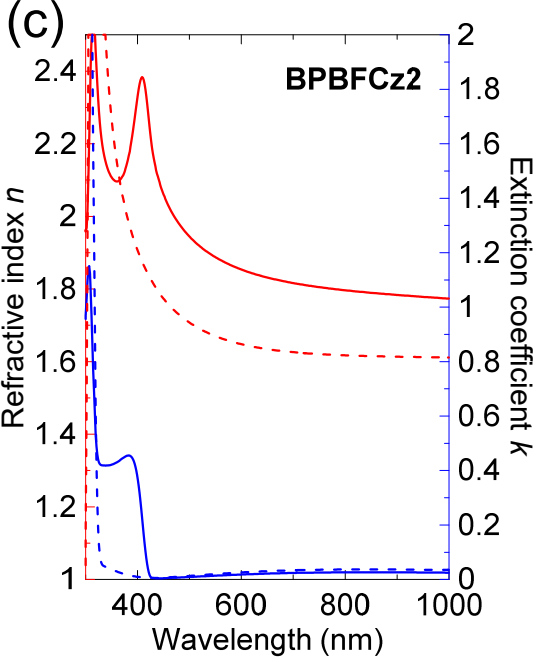

Figure S7. Variable-angle spectroscopic ellipsometry measurements of neat films of a) $\mathrm{BSBCz},{ }^{\mathrm{S} 5} \mathrm{~b}$ ) BPBFCz1, and c) BPBFCz2.

Table S4. Ordinary and extraordinary refractive indices and orientation order parameters of BSBCz, BPBFCz1, and BPBFCz2

\begin{tabular}{ccccc}
\hline Sample & $\begin{array}{c}\text { Ordinary refractive } \\
\text { index } n_{\mathrm{o}}{ }^{\text {b) }}\end{array}$ & $\begin{array}{c}\text { Extraordinary } \\
\text { refractive index } n_{\mathrm{e}} \text { b) }\end{array}$ & $\begin{array}{c}\text { Birefringence } \\
\Delta n=n_{\mathrm{o}}-n_{\mathrm{e}}\end{array}$ & $\begin{array}{c}\text { Orientation order } \\
\text { parameter } S^{\mathrm{c})}\end{array}$ \\
\hline $\mathrm{BSBCz}^{\mathrm{a})}$ & 1.95 & 1.69 & 0.26 & -0.36 \\
$\mathrm{BPBFCz} 1$ & 1.94 & 1.74 & 0.20 & -0.25 \\
$\mathrm{BPBFCz2}$ & 1.87 & 1.67 & 0.20 & -0.47 \\
\hline
\end{tabular}

${ }^{\text {a) }}$ Reference S5. ${ }^{\text {b) }}$ At $550 \mathrm{~nm} .{ }^{\mathrm{c})} S=\left(3 \cos ^{2} \theta-1\right) / 2=\left(k_{\mathrm{e}}-k_{\mathrm{o}}\right) /\left(k_{\mathrm{e}}+2 k_{\mathrm{o}}\right)$, where $k_{\mathrm{o}}$ and $k_{\mathrm{e}}$ are the ordinary and extraordinary extinction coefficients at the peak wavelength. 
(a)

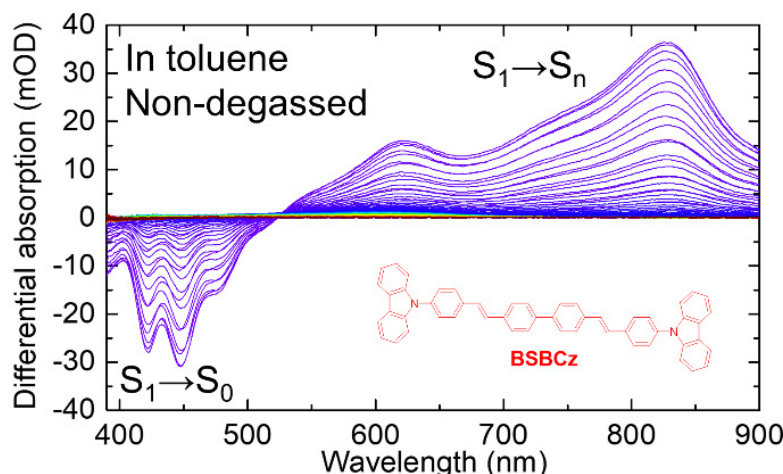

(c)

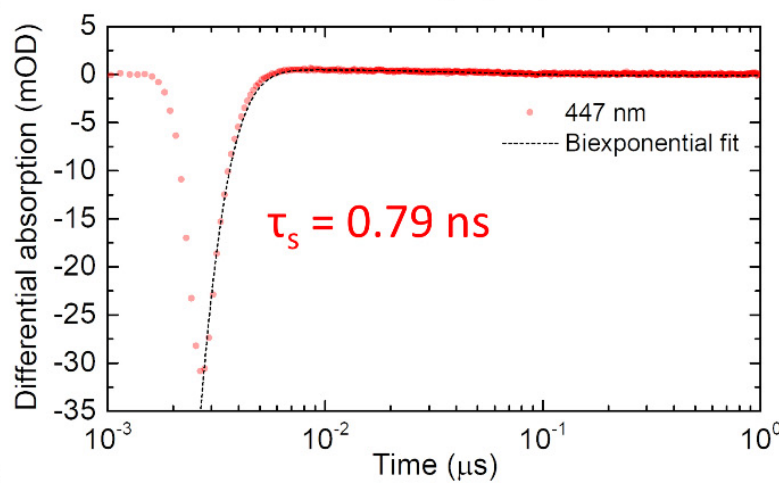

(e)

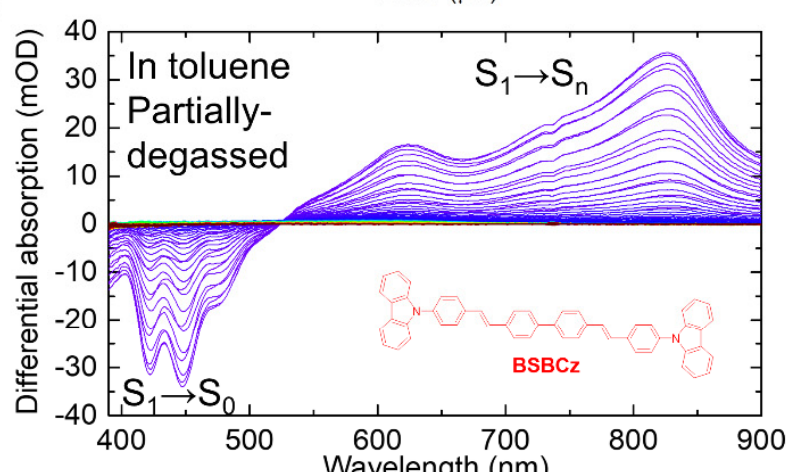

(g)

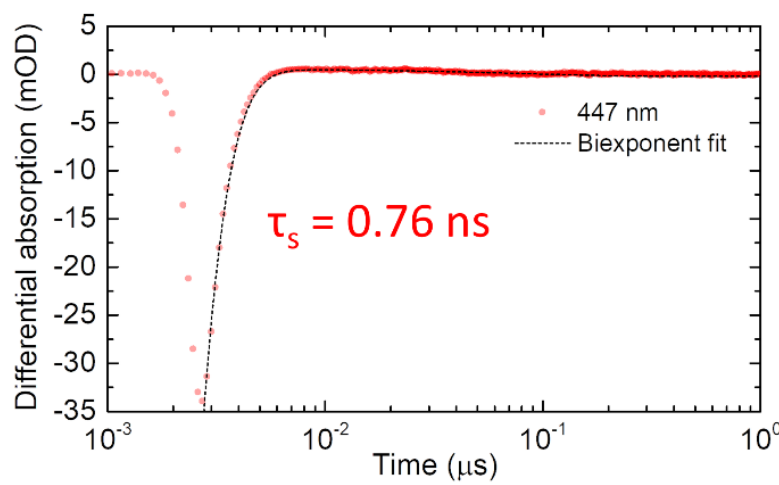

(b)

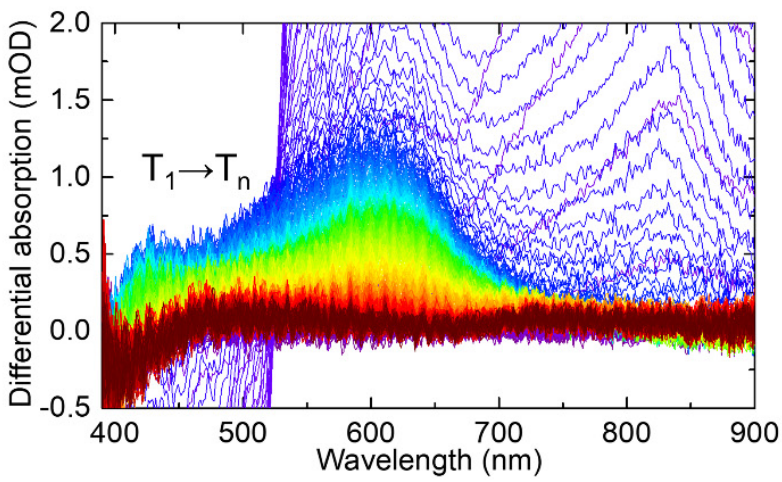

(d)

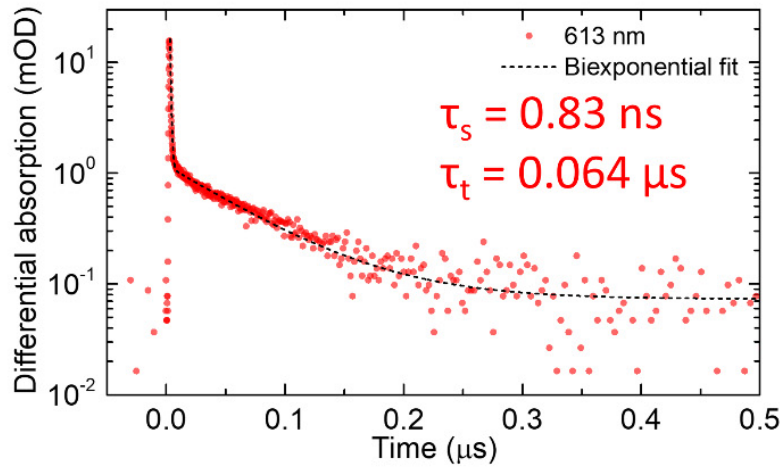

(f)

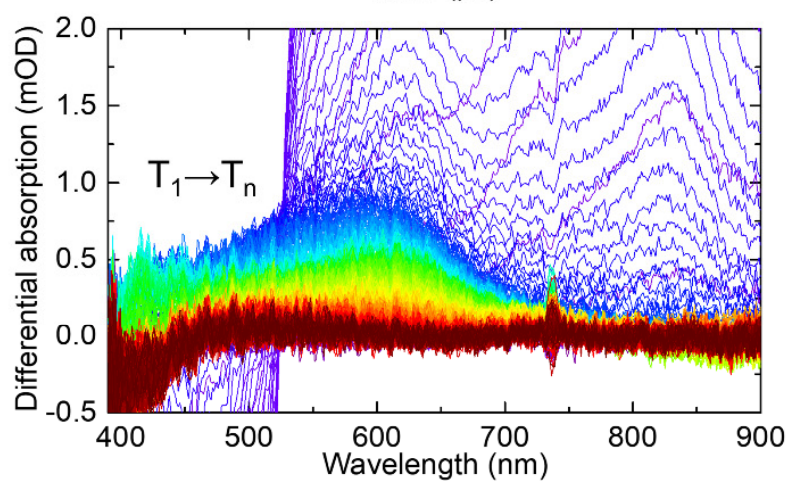

(h)

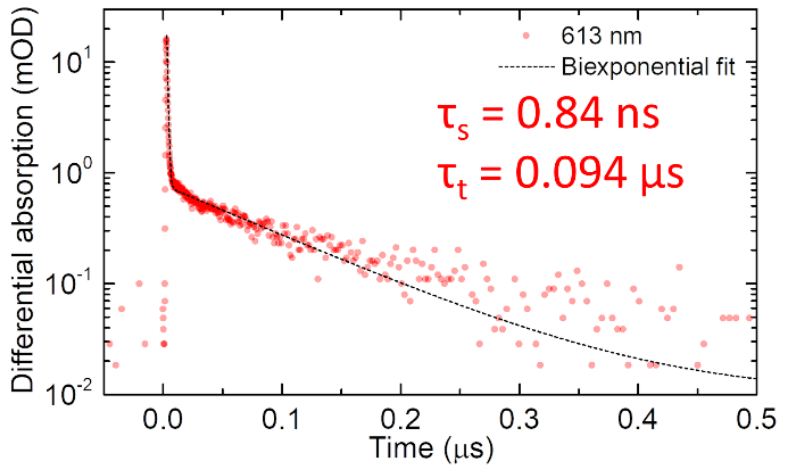

Figure S8. Excited-state absorption spectra of BSBCz in toluene. a), b), e) and f) Transient absorption spectra in non-degassed and partially-degassed toluene. Note that no triplet absorption signal was observed in fully degassed samples. c) and g) Decay at $447 \mathrm{~nm}$ showing no difference in decay of singlet emission upon degassing. d) and h) Decay at $613 \mathrm{~nm}$ showing longer lived nature of the triplet excited state in the absence of oxygen quenching. 
(a)

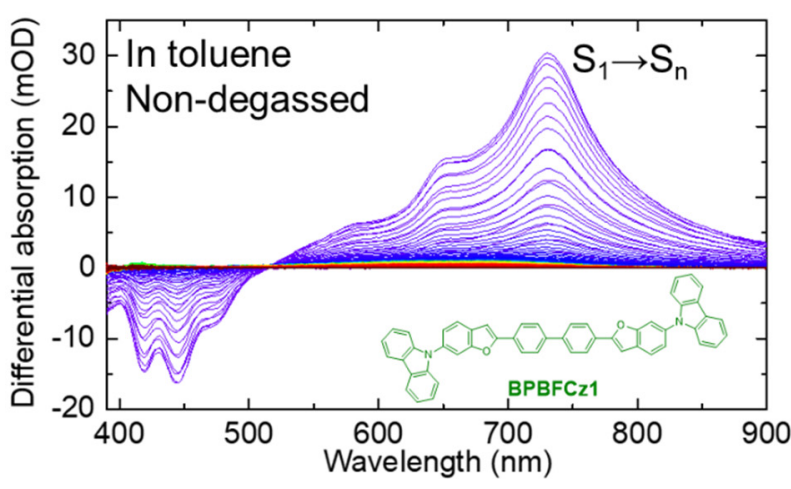

(c)

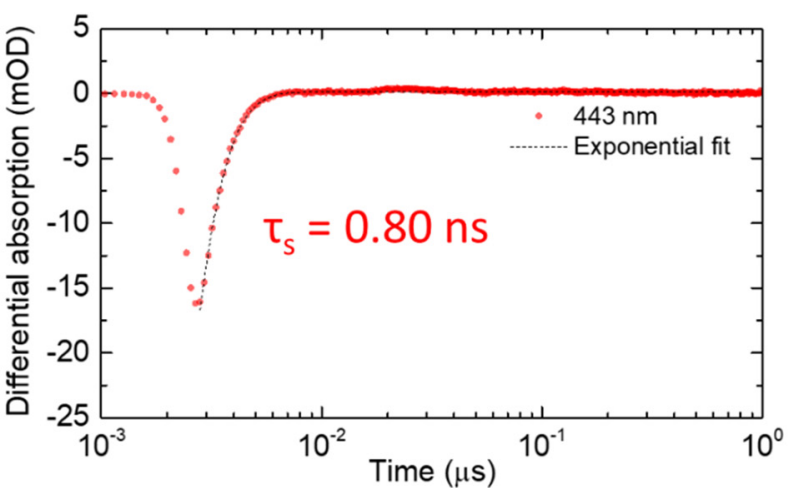

(e)

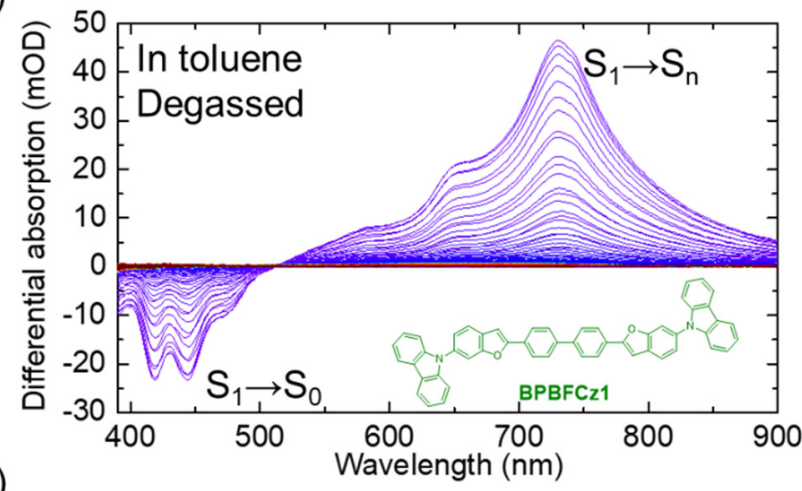

(g)

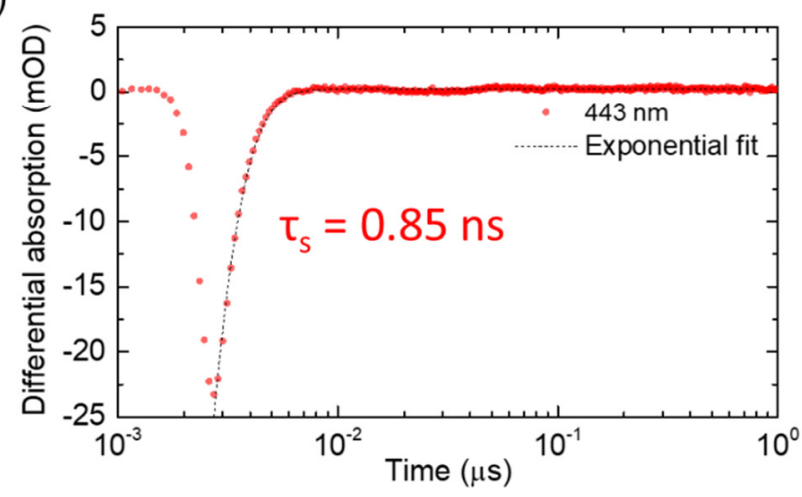

(b)

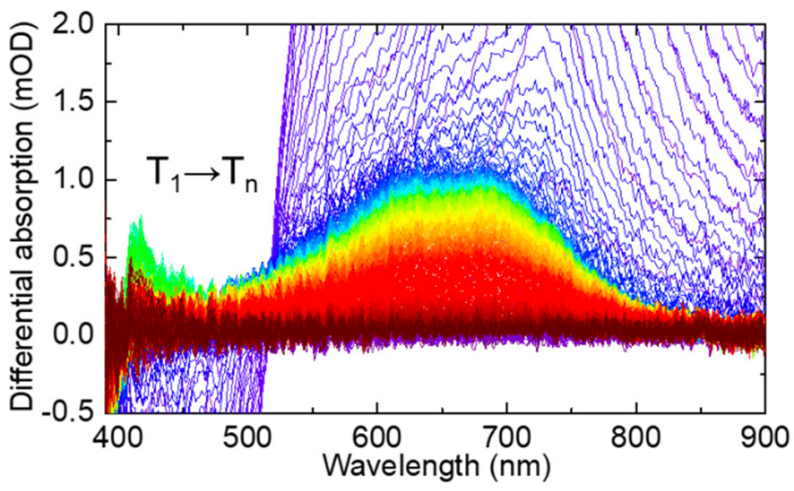

(d)

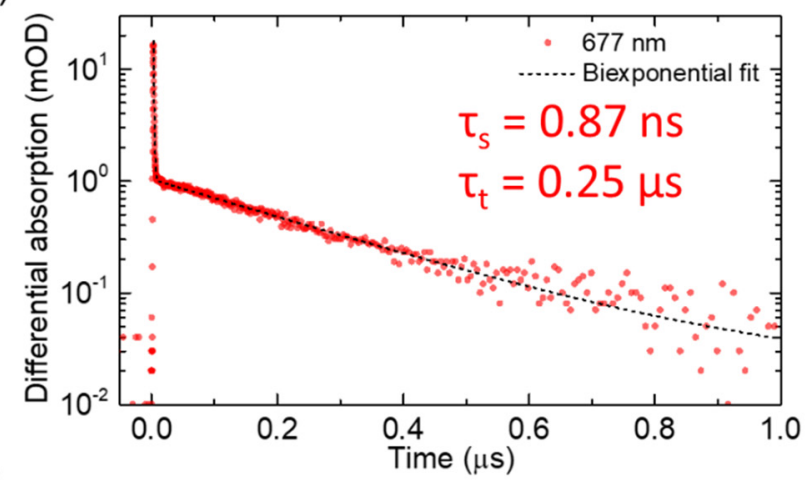

(f)

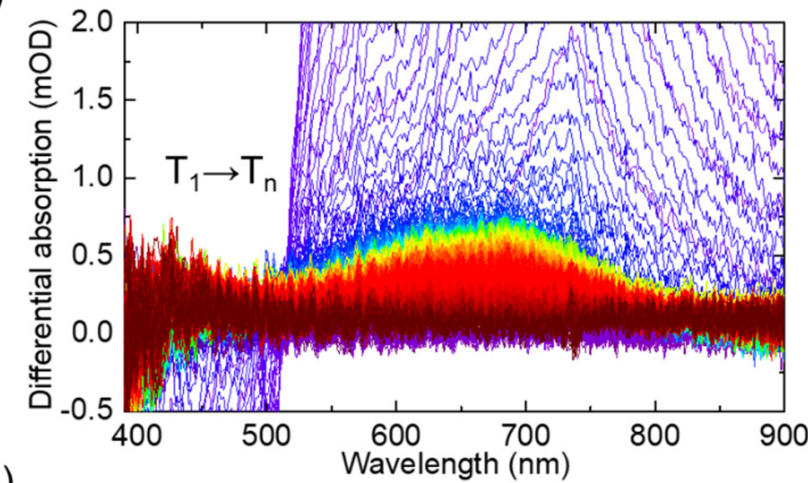

(h)

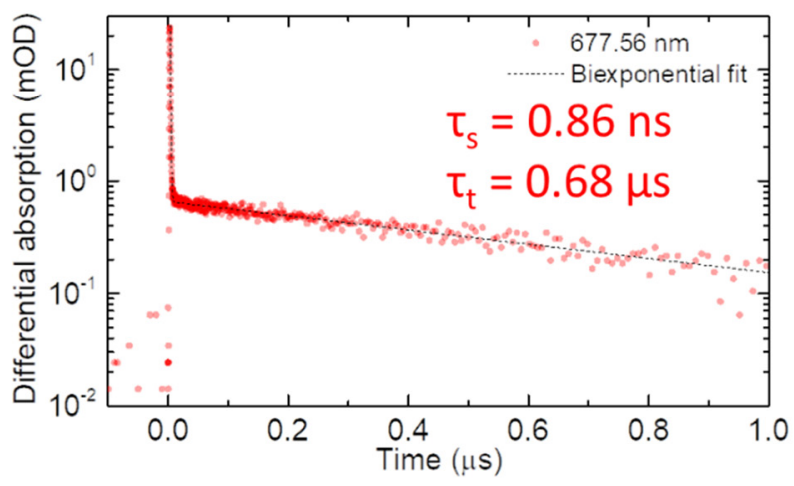

Figure S9. Excited-state absorption spectra of BPBFCz1 in toluene. a), b), e) and f) Transient absorption spectra in non-degassed and degassed toluene. c) and g) Decay at $443 \mathrm{~nm}$ showing no difference in decay dynamics of singlet emission upon degassing. d) and h) Decay at $677 \mathrm{~nm}$ showing longer lived nature of the triplet excited state in the absence of oxygen quenching. 
(a)

(c)
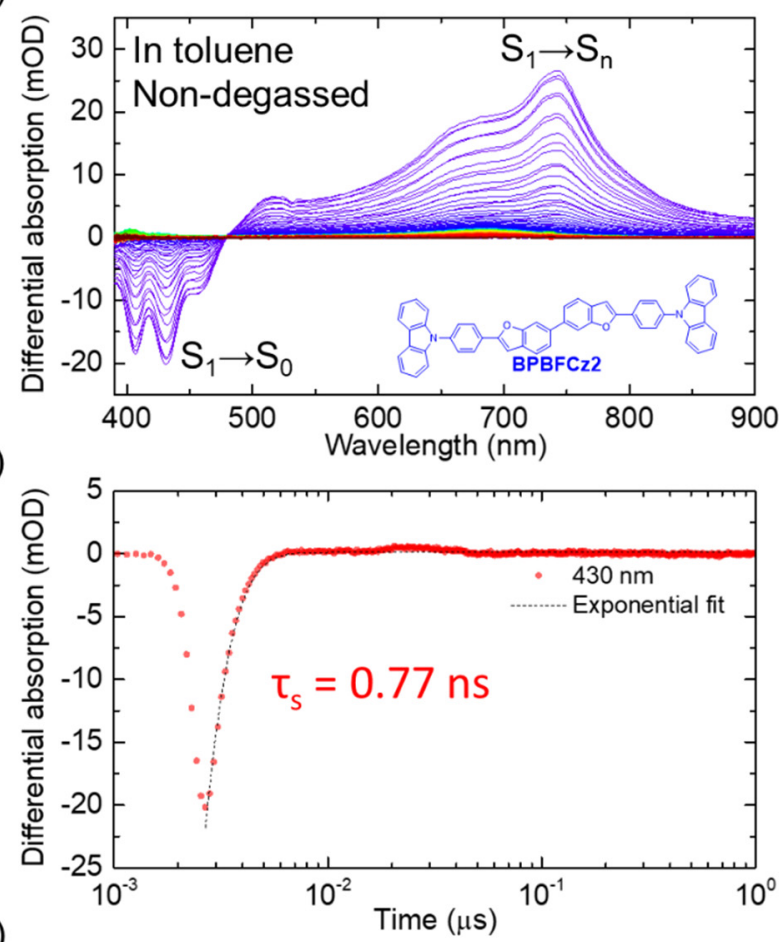

(e)

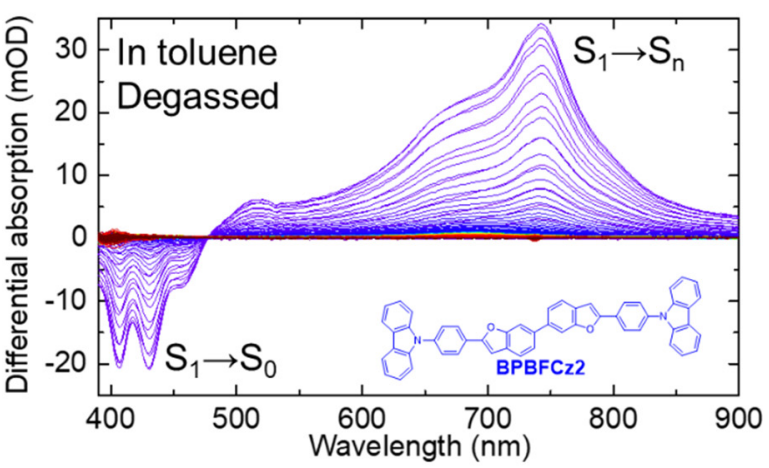

(g)

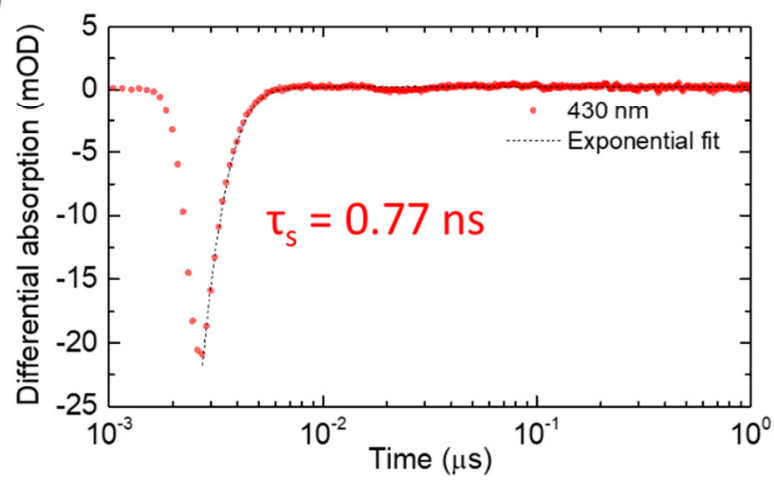

(b)

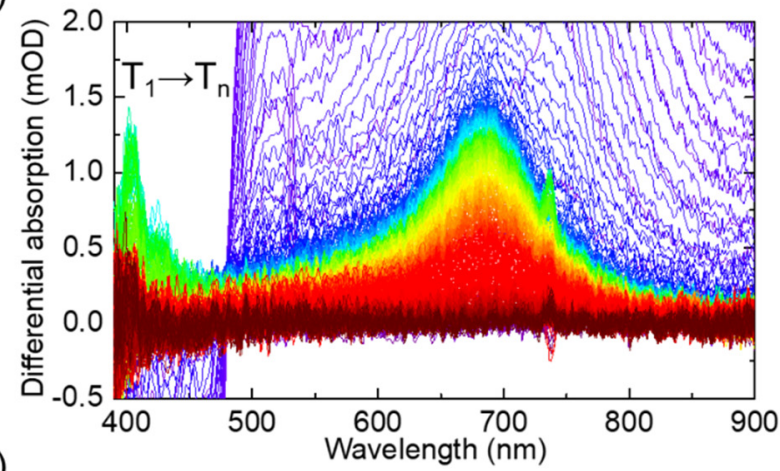

(d)

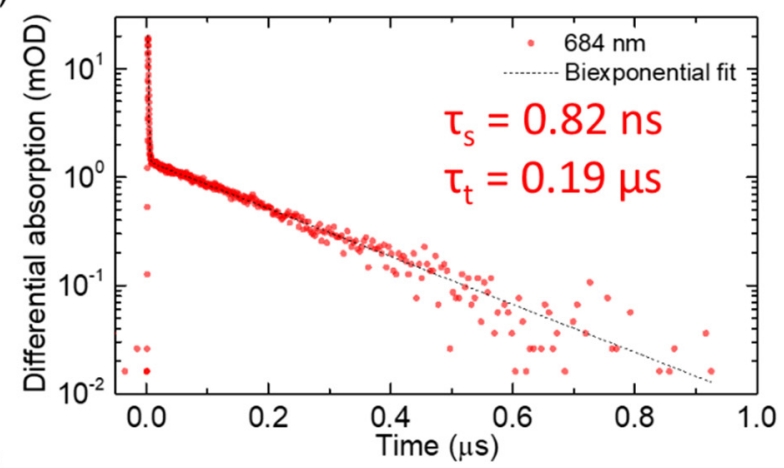

(f)

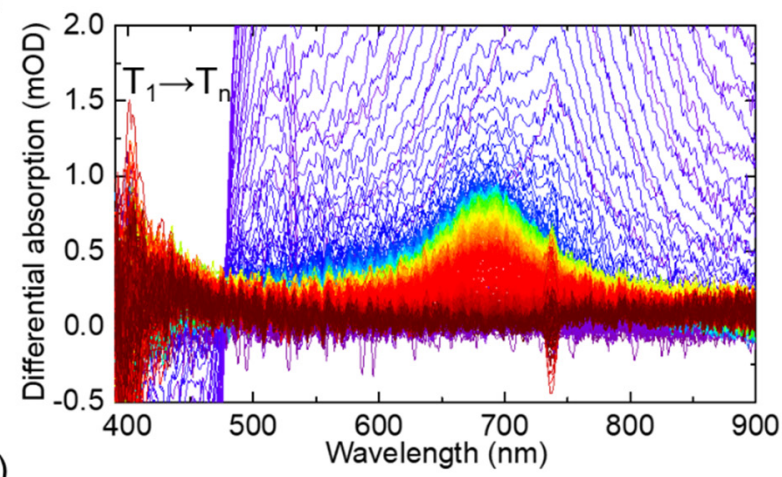

(h)

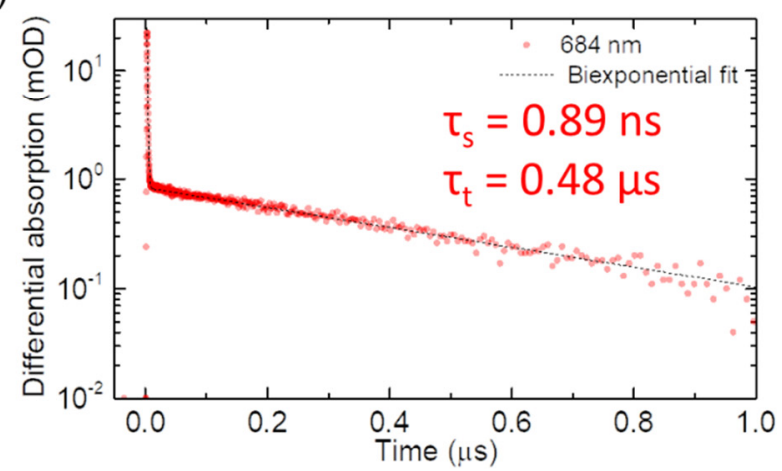

Figure S10. Excited-state absorption spectra of BPBFCz2 in toluene. a), b), e) and f) Transient absorption spectra in non-degassed and degassed toluene. c) and g) Decay at $430 \mathrm{~nm}$ showing no difference in decay dynamics of singlet emission upon degassing. d) and h) Decay at $684 \mathrm{~nm}$ showing longer lived nature of the triplet excited state in the absence of oxygen quenching. 
Methods S3. Calculation of cross sections

The absorption cross section is given by ${ }^{\mathrm{S} 6}$

$$
\sigma_{a b s}(\lambda)=\frac{1000 \varepsilon(\lambda) \ln 10}{N_{A}}
$$

Here, $\varepsilon(\lambda)$ is the molar absorption coefficient and $N_{\mathrm{A}}$ is the Avogadro number. Note that it may include small error because of low solubility of compounds.

The stimulated emission cross section is given by

$$
\sigma_{e m}(\lambda)=\frac{\lambda^{4} E_{f}(\lambda)}{8 \pi n^{2}(\lambda) c \tau}
$$

Here, $E_{f}(\lambda)$ corresponds to the distribution of the PL efficiency, $n(\lambda)$ is the dispersion of the refractive index, $\tau_{f}$ is the fluorescence lifetime.

The triplet excited-states absorption cross sections of BPBFCz1 and BPBFCz2 are estimated from the value of $\mathrm{BSBCz}$ as a reference $\left(3.89 \times 10^{-17} \mathrm{~cm}^{2}\right.$ at $\left.630 \mathrm{~nm}\right)$ and can be expressed by equation: ${ }^{\mathrm{S} 7}$

$$
\left(\sigma_{T T}(\lambda)\right)_{\text {sample }}=\left|\sigma_{T T}\right|_{\text {ref }} \frac{\left(\phi_{I S C}\right)_{\text {ref }}}{\left(\Delta O D_{\text {max }}\right)_{\text {ref }}} \frac{\left(\Delta O D_{\text {max }}\right)_{\text {sample }}}{\left(\phi_{I S C}\right)_{\text {sample }}} T(\lambda)
$$

Here, $\left(\sigma_{\mathrm{TT}}(\lambda)\right)_{\text {sample }}$ is triplet absorption cross section spectra of sample, $\left|\sigma_{\mathrm{TT}}\right|_{\text {ref }}$ is peak triplet absorption cross section of reference, $\phi_{\mathrm{ISC}}$ is intersystem crossing yield of reference and sample, $\triangle O D_{\max }$ is peak differential absorption signal for triplet excited-states of reference and sample, and $T(\lambda)$ is normalized triplet absorption spectra of sample.

The $\phi_{\mathrm{ISC}}$ of BSBCz is reported to be 0.04 . The $\phi_{\mathrm{PL}}$ of BPBFCz1 and BPBFCz2 are 0.96 , indicating $\phi_{\mathrm{ISC}}<0.04$ and small difference of $\phi_{\mathrm{ISC}}$ between BSBCz and BPBFCz. Therefore, the $\sigma_{\mathrm{TT}}$ of BPBFCz were calculated from the following equation:

$$
\left(\sigma_{T T}(\lambda)\right)_{\text {sample }}=\left|\sigma_{T T}\right|_{\text {ref }} \frac{\left(\Delta O D_{\text {max }}\right)_{\text {sample }}}{\left(\Delta O D_{\text {max }}\right)_{\text {ref }}} T(\lambda)
$$

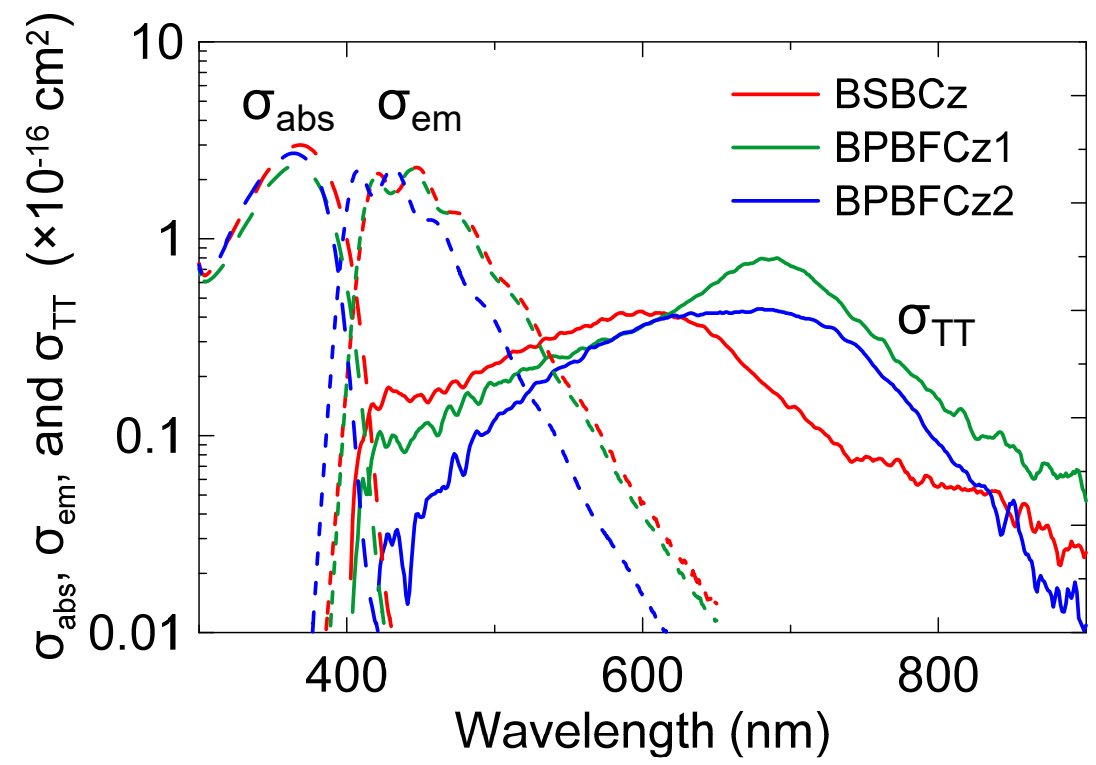

Figure S11. Absorption, stimulated emission, and triplet excited-states absorption cross sections for $\mathrm{BSBC} z, \mathrm{BPBFCz} 1$, and BPBFCz2 in solution. 
(a)

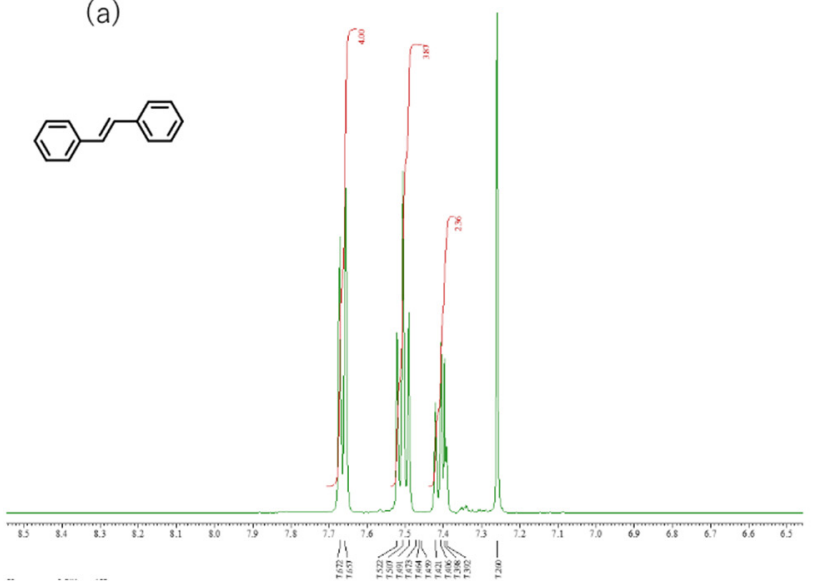

(b)

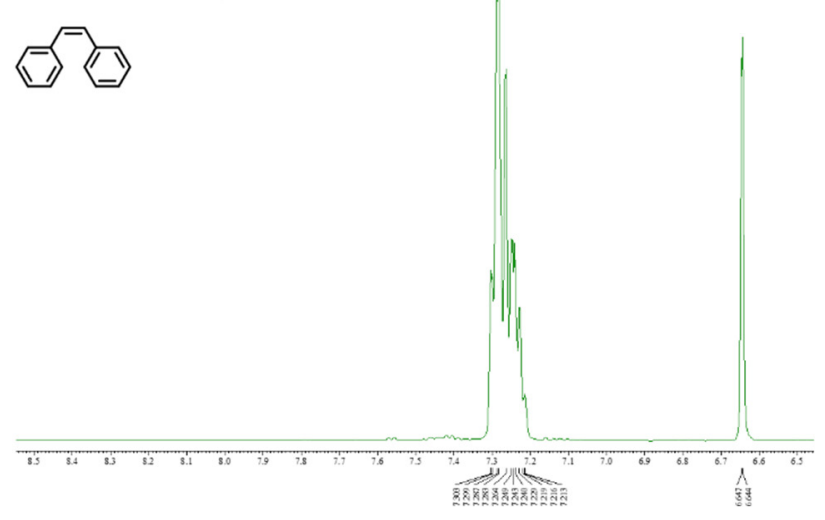

Figure S12. ${ }^{1} \mathrm{H}$ NMR spectra of stilbene in $\mathrm{CDCl}_{3}$. (a) trans-stilbene and (b) cis-stilbene.

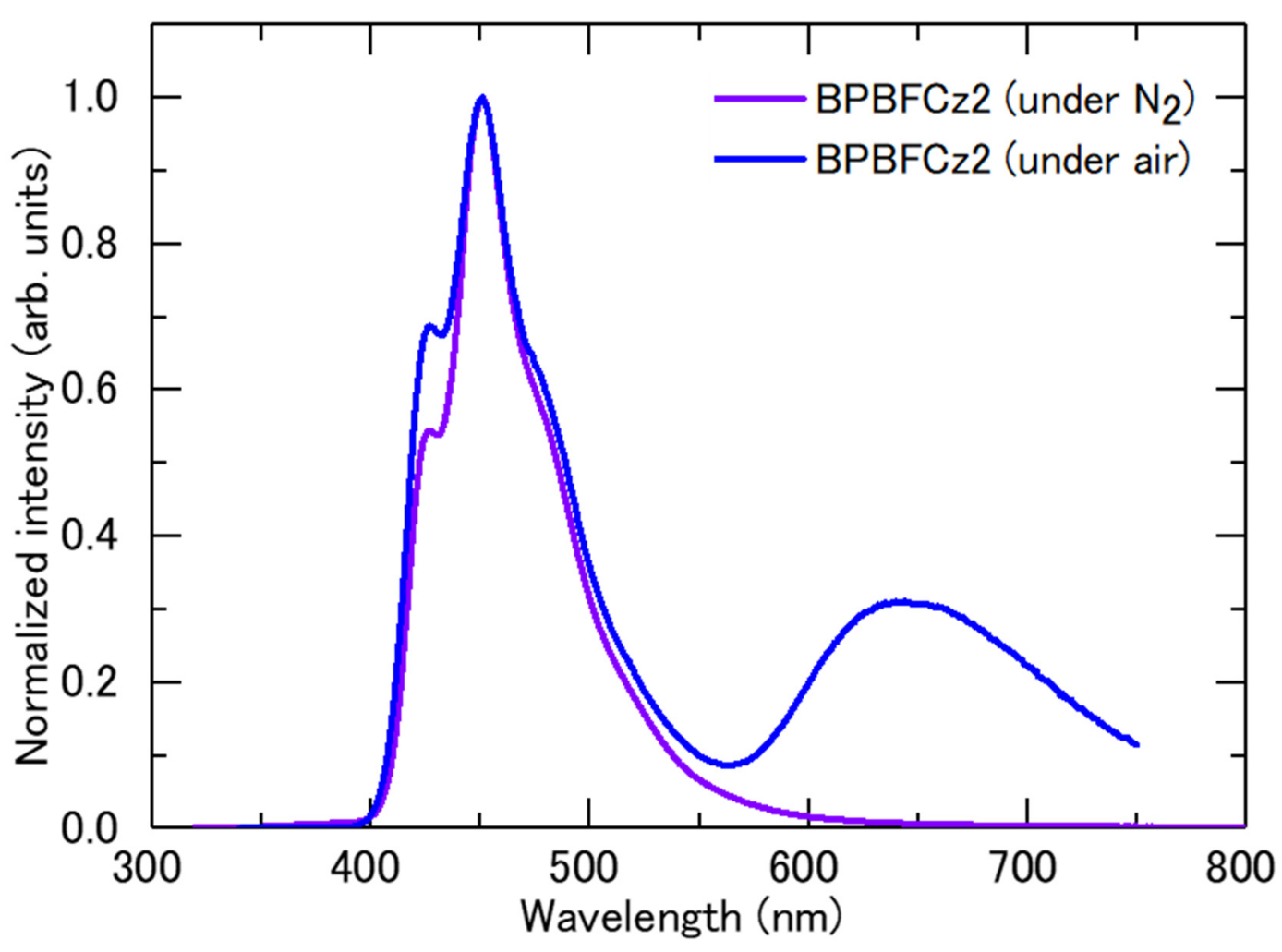

Figure S13. PL spectra for BPBFCz2 neat film under air and $\mathrm{N}_{2}$. Excitation wavelength $=300 \mathrm{~nm}$. 


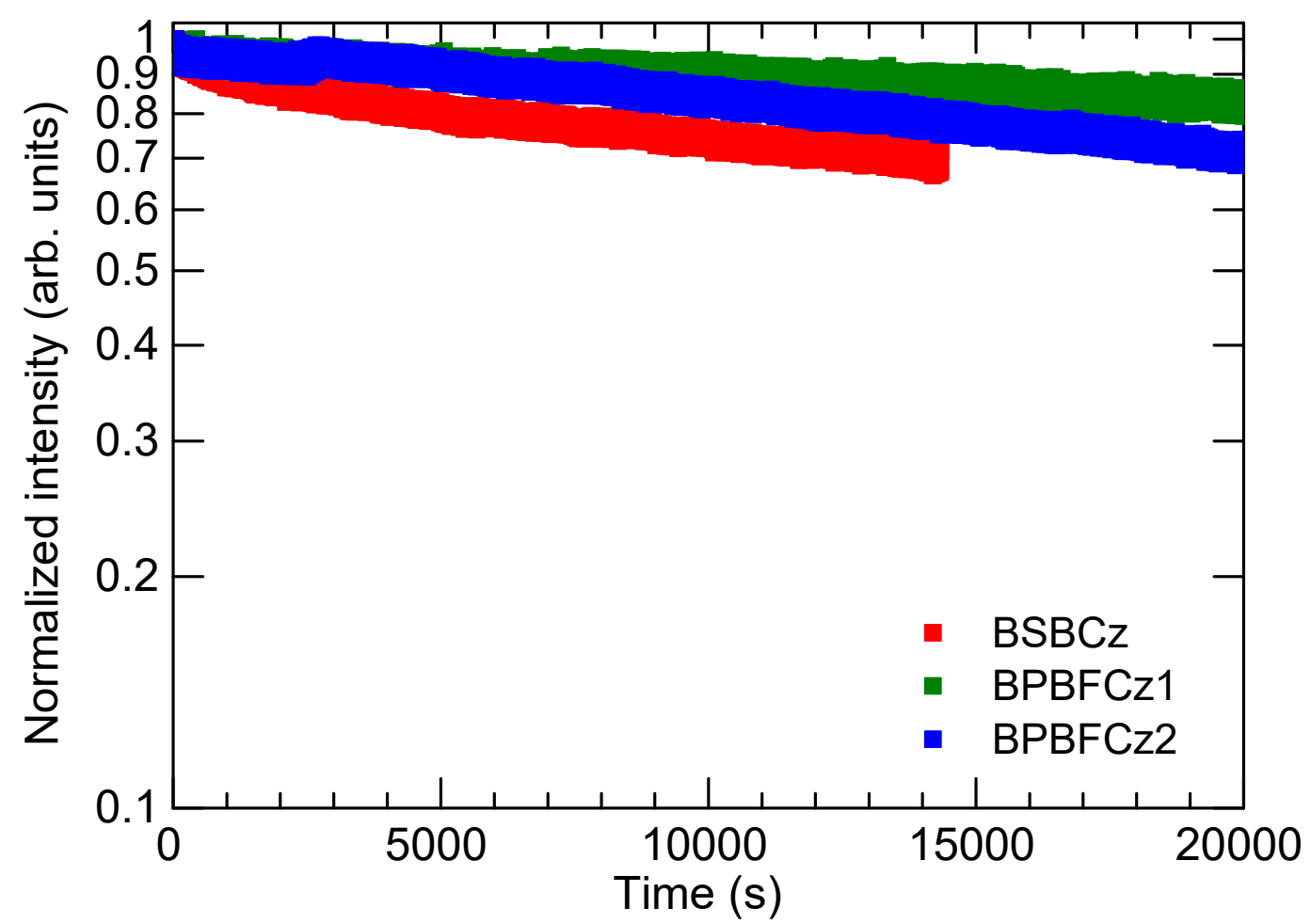

Figure S14. ASE intensity normalized to the initial for $\mathrm{BSBC} z, \mathrm{BPBFCz} 1$, and BPBFCz2 neat films as a function of measurement time. The excitation intensity was $950 \mu \mathrm{J} \mathrm{cm}^{-2}$ at $337 \mathrm{~nm}$ with a nitrogen gas laser.

Table S5. Materials

\begin{tabular}{lll}
\hline Reagents & CAS No. & Supplier, code, and grade \\
\hline Bromoacetaldehyde diethyl acetal & $2032-35-1$ & Tokyo Kasei Co., Ltd., B0957. \\
3-Bromophenol & $591-20-8$ & Tokyo Kasei Co., Ltd., B0629. \\
Sodium hydride, in oil & $7646-69-7$ & WAKO Chemical Industries, 191-07662. \\
$N, N$-Dimethylformamide & $68-12-2$ & WAKO Chemical Industries, 043-02917. \\
H- $\beta$ zeolite & $1318-02-1$ & TOSOH Co., HSZ-980HA \\
Carbazole & $86-74-8$ & Tokyo Kasei Co., Ltd., C0032. \\
Palladium(II)acetate & $3375-31-3$ & WAKO Chemical Industries, 161-24703. \\
Tri-t-butylphosphine & $13716-12-6$ & WAKO Chemical Industries, 208-18513. \\
Iodine & $7553-56-2$ & WAKO Chemical Industries, 092-05422. \\
$n$-Butyllithium solution, 2.5 M in hexanes & $109-72-8$ & Aldrich Chemical Co., 230707. \\
4-(9-Carbazolyl)phenylboronicacid & $419536-33-7$ & WAKO Chemical Industries, 357-18813. \\
Tetrakis(triphenylphosphine)palladium(0) & $14221-01-3$ & WAKO Chemical Industries, 216666. \\
4,4"-Biphenyldiboronic Acid & $4151-80-8$ & Tokyo Kasei Co., Ltd., B2490. \\
Potassium Carbonate & $584-08-7$ & WAKO Chemical Industries, 162-03495. \\
\hline
\end{tabular}


Table S6. Instruments

\begin{tabular}{|c|c|c|}
\hline Instruments & Brands and types & Conditions \\
\hline Sublimation & ALS technology & Three-zone sublimation apparatus \\
\hline Elemental analyses & Yanaco MT-5 CHN corder & \\
\hline MS & Waters 3100 Mass Spectrometer & Direct probe ionization, ASAP-MS \\
\hline MS & Shimadzu AXIMA Confidence & MALDI-MS, Reflection mode \\
\hline NMR & $\begin{array}{l}\text { Bruker AVANCE III } 500 \mathrm{MHz} \\
\text { spectrometer }\end{array}$ & $\begin{array}{l}\text { Chemical shifts were calibrated to the } \\
\text { corresponding deuterated solvents. } \\
7.26 \text { ppm for } \mathrm{CDCl}_{3} \text { in }{ }^{1} \mathrm{H} \text { NMR, and } 77.2 \mathrm{ppm} \text { for } \\
\mathrm{CDCl}_{3} \text { in }{ }^{13} \mathrm{C} \mathrm{NMR}^{-}\end{array}$ \\
\hline TG-DTA & Bruker TG-DTA 2400SA, & $\begin{array}{l}\text { Under a } \mathrm{N}_{2} \text { atmosphere or } 1 \mathrm{~Pa} \text { with a heating rate } \\
\text { of } 10^{\circ} \mathrm{C} \text { per minute }\end{array}$ \\
\hline UV-Vis & $\begin{array}{l}\text { Perkin-Elmer Lambda 950-PKA } \\
\text { UV-vis spectrophotometer }\end{array}$ & $\begin{array}{l}\text { The light source consisted of Deuterium (D2) and } \\
\text { Tungsten Iodide }(50 \mathrm{~W}) \text { lamps for the ultraviolet and } \\
\text { visible regions. }\end{array}$ \\
\hline PL & JASCO FP-8600 fluorometer & $\begin{array}{l}\text { The excitation wavelength was set to the absorption } \\
\text { maximum. }\end{array}$ \\
\hline PL quantum yield & $\begin{array}{l}\text { Hamamatsu Photonics } \\
\text { Quantaurus-QY C11347-01 }\end{array}$ & $\begin{array}{l}\text { Absolute PL quantum yield. The measurement error } \\
\text { for the obtained QY values on this instrument is } \\
\pm 3 \% \text {. }\end{array}$ \\
\hline $\begin{array}{l}\text { Transient photo- } \\
\text { luminescence decay }\end{array}$ & $\begin{array}{l}\text { Hamamatsu Photonics } \\
\text { Quantaurus-Tau C11367-03 }\end{array}$ & \\
\hline CV/DPV & $\begin{array}{lcc}\text { BAS } \quad 608 \mathrm{D}+ & \text { DPV } \\
\text { Electrochemical system } & \end{array}$ & $\begin{array}{l}\text { Supporting electrolyte: tetrabutylammonium } \\
\text { hexafluorophosphate }\left(\mathrm{TBAPF}_{6}\right) \quad\left(\begin{array}{ll}0.1 & \mathrm{M})\end{array} \text { in }\right. \\
\text { dichloromethane } \\
\text { Working electrode: platinum } \\
\text { Auxiliary electrode: a platinum wire } \\
\text { Reference electrode: an } \mathrm{Ag} / \mathrm{AgNO}_{3} \\
\text { Calibration: ferrocenium-ferrocene }\left(\mathrm{Fc} / \mathrm{Fc}^{+}\right) \text {as a } \\
\text { standard } \\
\text { Scan rate: } 100 \mathrm{mV} \mathrm{s}^{-1} \text { for } \mathrm{CV}\end{array}$ \\
\hline $\begin{array}{l}\text { Photoelectron yield } \\
\text { spectroscopy (PYS) }\end{array}$ & Riken Keiki, AC-3 & In air \\
\hline Surface profiler & Bruker Dektak XT & $\begin{array}{l}\text { Tip radius of } 12.5 \mu \mathrm{m} \text { and a scan resolution of } 0.168 \\
\mu \mathrm{m} / \text { point }\end{array}$ \\
\hline XRD & $\begin{array}{l}\text { Rigaku Ultima } \\
\text { diffractometer }\end{array}$ & $40 \mathrm{kV}$ and $40 \mathrm{~mA}$ using $\mathrm{CuK} \alpha$ radiation \\
\hline UV/ozone & $\begin{array}{l}\text { Nippon Laser \& Electronics } \\
\text { Lab. NL-UV253 }\end{array}$ & $15 \min$ \\
\hline $\begin{array}{l}\text { Variable-angle } \\
\text { spectroscopic } \\
\text { ellipsometry (VASE) }\end{array}$ & J.A. Wollam, M-2000U & $\begin{array}{l}\text { Different angles from } 45^{\circ} \text { to } 75^{\circ} \text { by steps of } 5^{\circ} \\
\text { Analytical software: J.A. Woollam, WVASE } 32\end{array}$ \\
\hline
\end{tabular}




\section{Methods S4. Experimental details}

Film sample preparation: Thin films were fabricated on clean quartz substrates for optical measurements, on nonfluorescent glass (MATSUNAMI slide glass S0313) for ASE measurements, and silicon substrates for the variableangle spectroscopic ellipsometry and XRD. The substrates were cleaned with acetone and isopropanol and then treated with UV/ozone to remove adsorbed organic species before deposition. Films were prepared by thermal evaporation at a pressure lower than $7 \times 10^{-4} \mathrm{~Pa}$. The deposition rates were $1.0 \AA / \mathrm{s}$ for neat films and $0.1 \AA / \mathrm{s}$ for the guest and $1.7 \AA / \mathrm{s}$ for the host for doped films ( $6 \mathrm{wt} \%)$. The doping concentration of $6 \mathrm{wt} \%$ is widely used and a common condition for BSBCz. The film thicknesses for ASE measurements were $120 \mathrm{~nm}$ for the doped films and $100 \mathrm{~nm}$ for the neat films, which are optimized values for BSBCz. The thicknesses were measured using a surface profiler and an ellipsometry.

ASE measurements: ASE properties of the thin films were characterized by optically pumping with a randomly polarized nitrogen gas laser (KEN2020, Usho Optical Systems Co., Ltd.) at an excitation wavelength of $337 \mathrm{~nm}$ with a $0.8 \mathrm{~ns}$ pulse (operating frequency of $10 \mathrm{~Hz}$ ). The input laser beam was focused into a stripe with dimensions of 0.6 $\mathrm{cm} \times 0.1 \mathrm{~cm}$ using a cylindrical lens. Neutral density filters were used to adjust excitation intensity. ASE measurements were performed under a nitrogen atmosphere to prevent degradation. Output light emission from the edge of the sample was collected into an optical fiber connected to a spectrometer (Hamamatsu Photonics PMA-12. ASE thresholds were identified from the plot of output versus input intensity. Reproducibility was confirmed by measuring at least five different samples.

Transient Absorption Spectroscopy Measurements: Nano-second transient absorption spectra were measured using a broadband pump-probe spectrometer (EOS, Ultrafast Systems, LLC). The sample solutions were prepared by dissolving BPBFCz1, BPBFCz2 and BSBCz in toluene to provide an optical density of 0.3 at $370 \mathrm{~nm}$ in a quartz cuvette with a path length of $2 \mathrm{~mm}$. An amplified laser system (Spitfire ACE, Spectra Physics) was the excitation source, delivering $c a .100 \mathrm{fs}$ laser pulses at $800 \mathrm{~nm}$ with a $1 \mathrm{kHz}$ repetition rate, which were then coupled to an OPA system (Topas Prime, Light Conversion), to deliver 'pump' pulses tuned to $370 \mathrm{~nm}$. A white light continuum 'probe' (ca. 380-900 nm) was generated using a pulsed Nd:YAG based Leukos-STM super continuum light source, the timing of which was controlled via the sync trigger from the amplified laser system. The samples were measured in ambient and degassed conditions, respectively. The degassing of samples was carried out through several freezethaw-pump cycles. Absorption spectra of before and after the measurements confirmed no degradation owing to the pump beam.

Photostability evaluation: A CW laser diode (Coherent OBIS LG 355-20) was used to generate excitation light with an excitation wavelength of $355 \mathrm{~nm}$. The excitation power was $\mathrm{xx} \mathrm{mW} \mathrm{cm}{ }^{-2}$. Changes in PL were monitored using a PMA-12. 
Data S1. NMR spectra

(1)

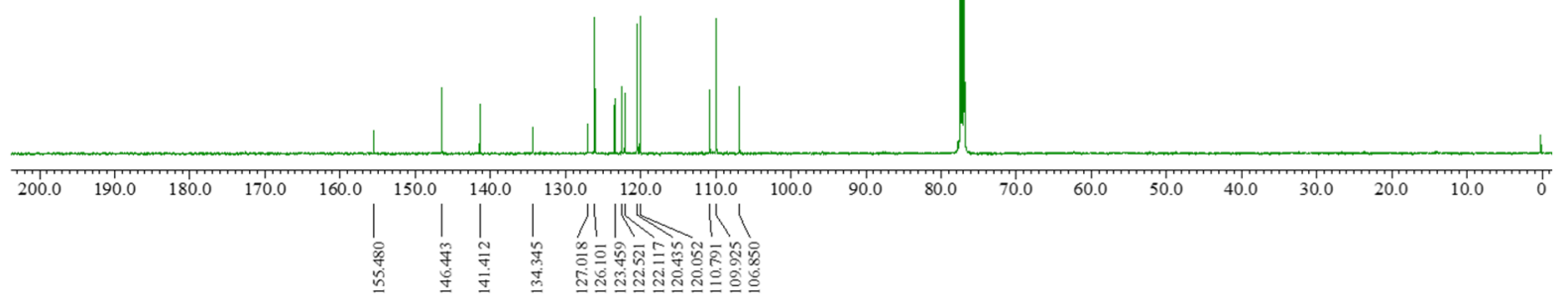

(1)

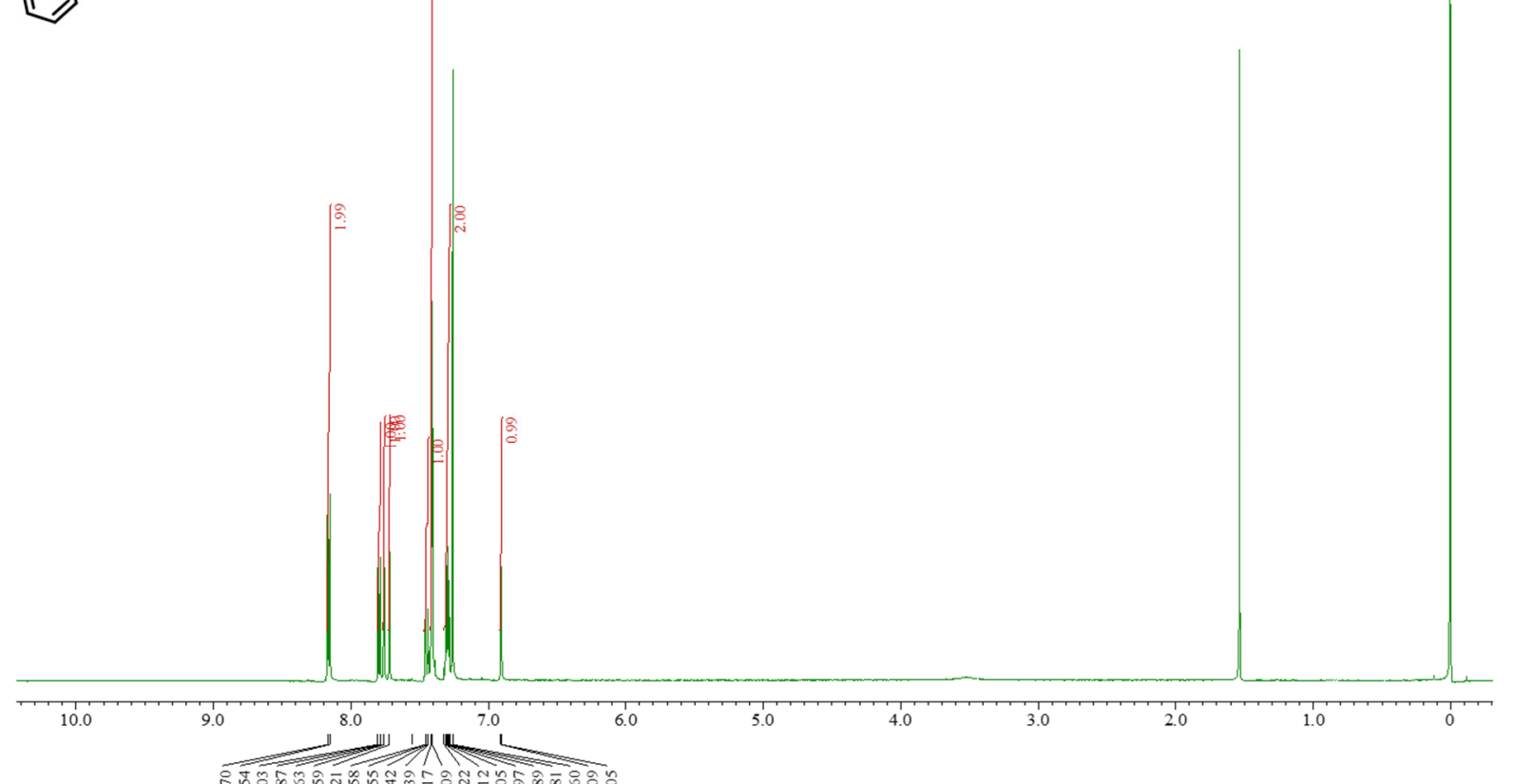

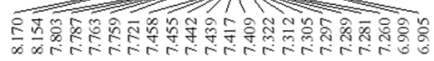



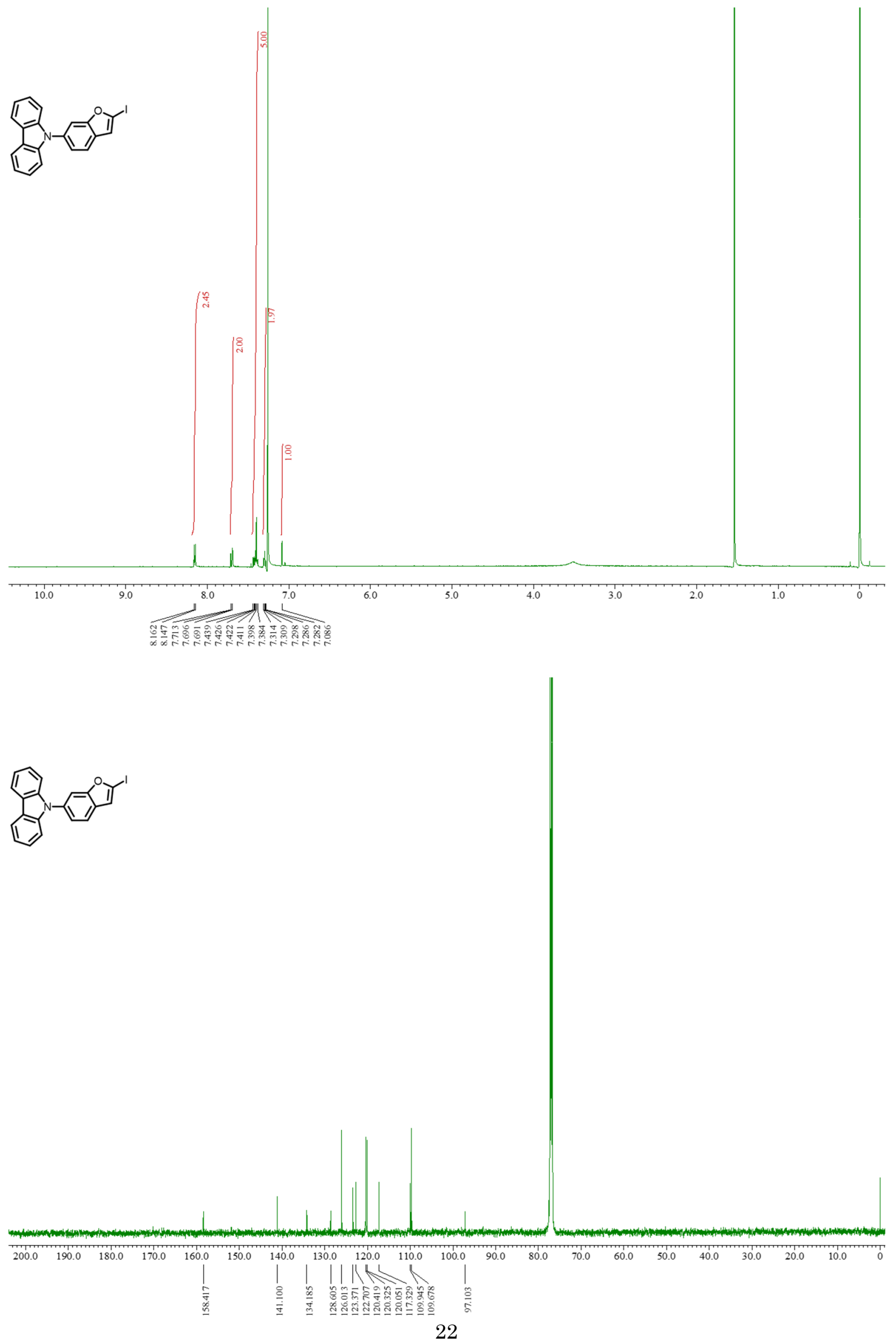


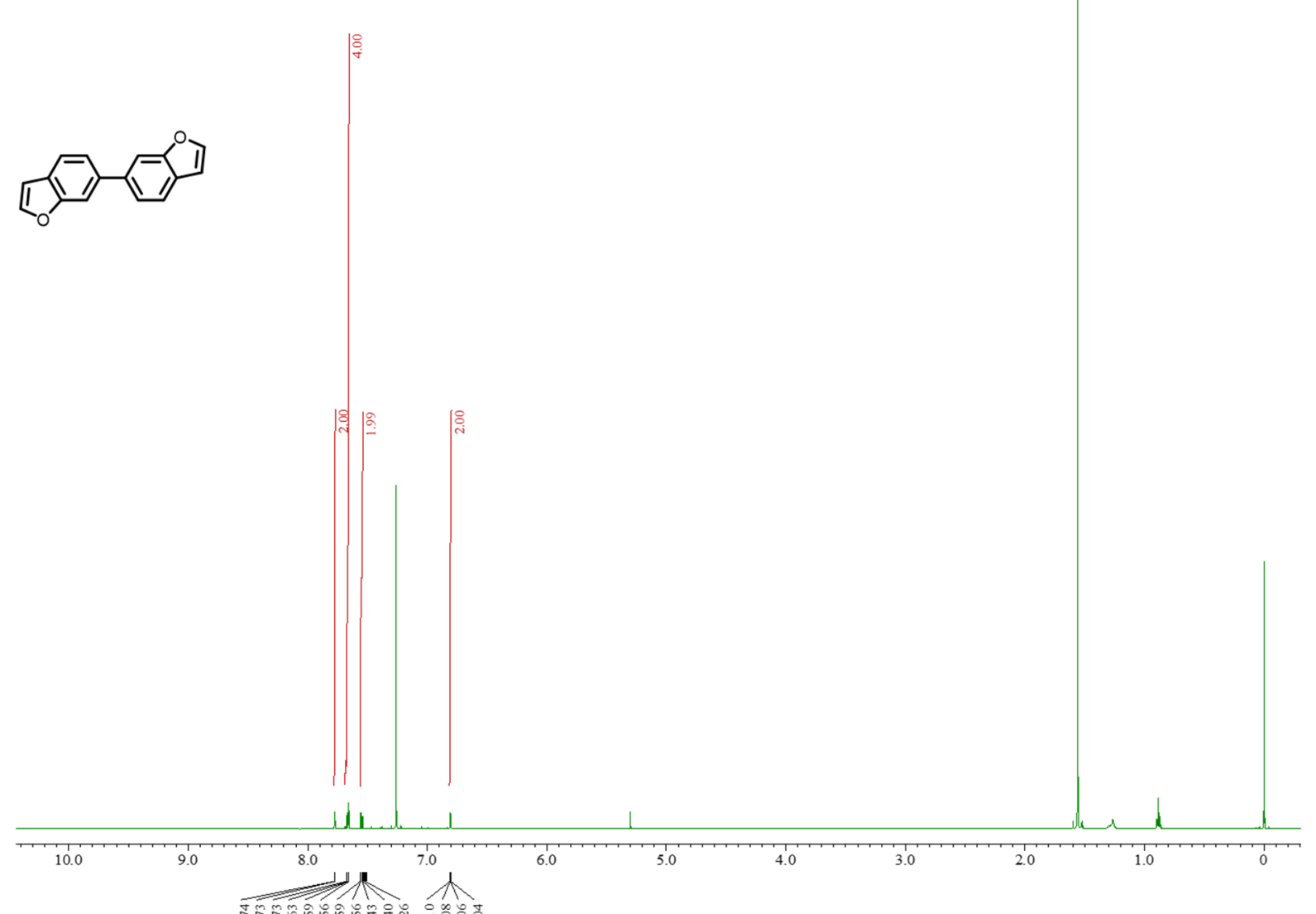

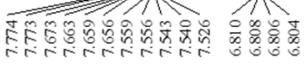

(1)

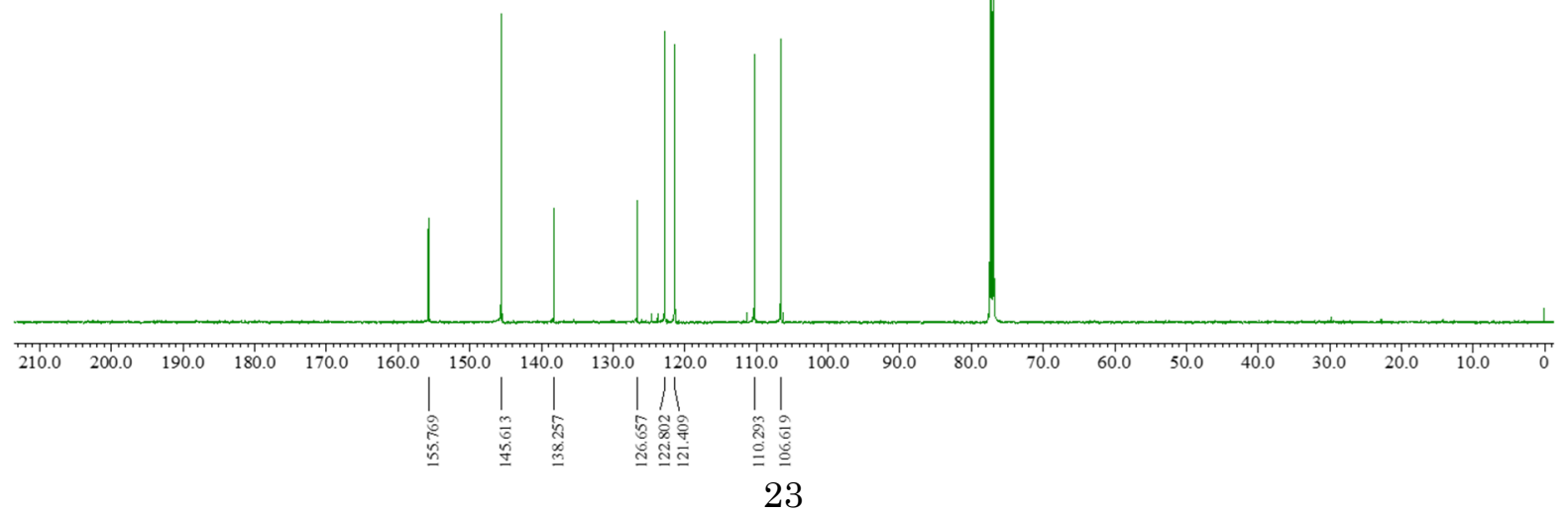



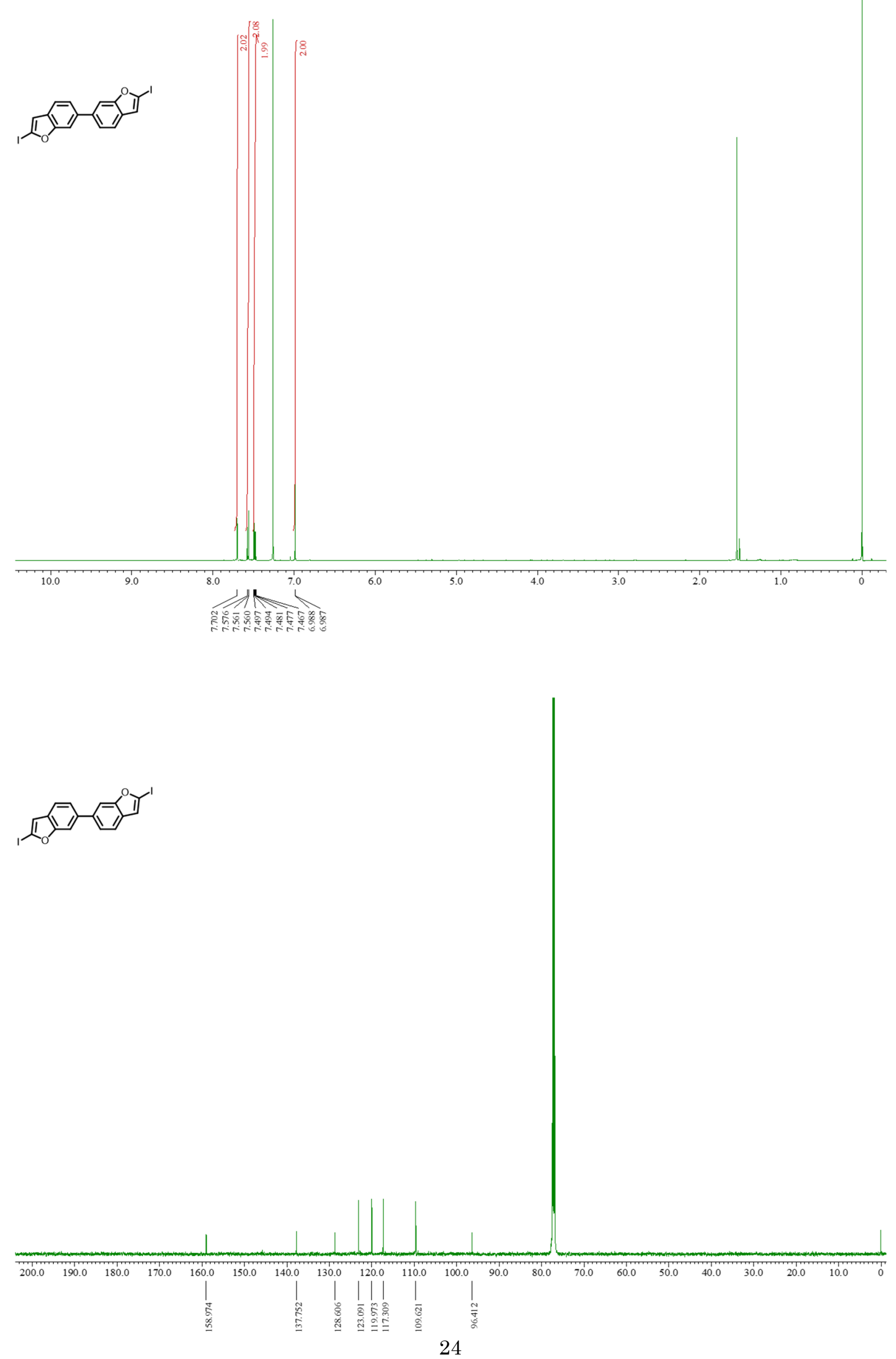

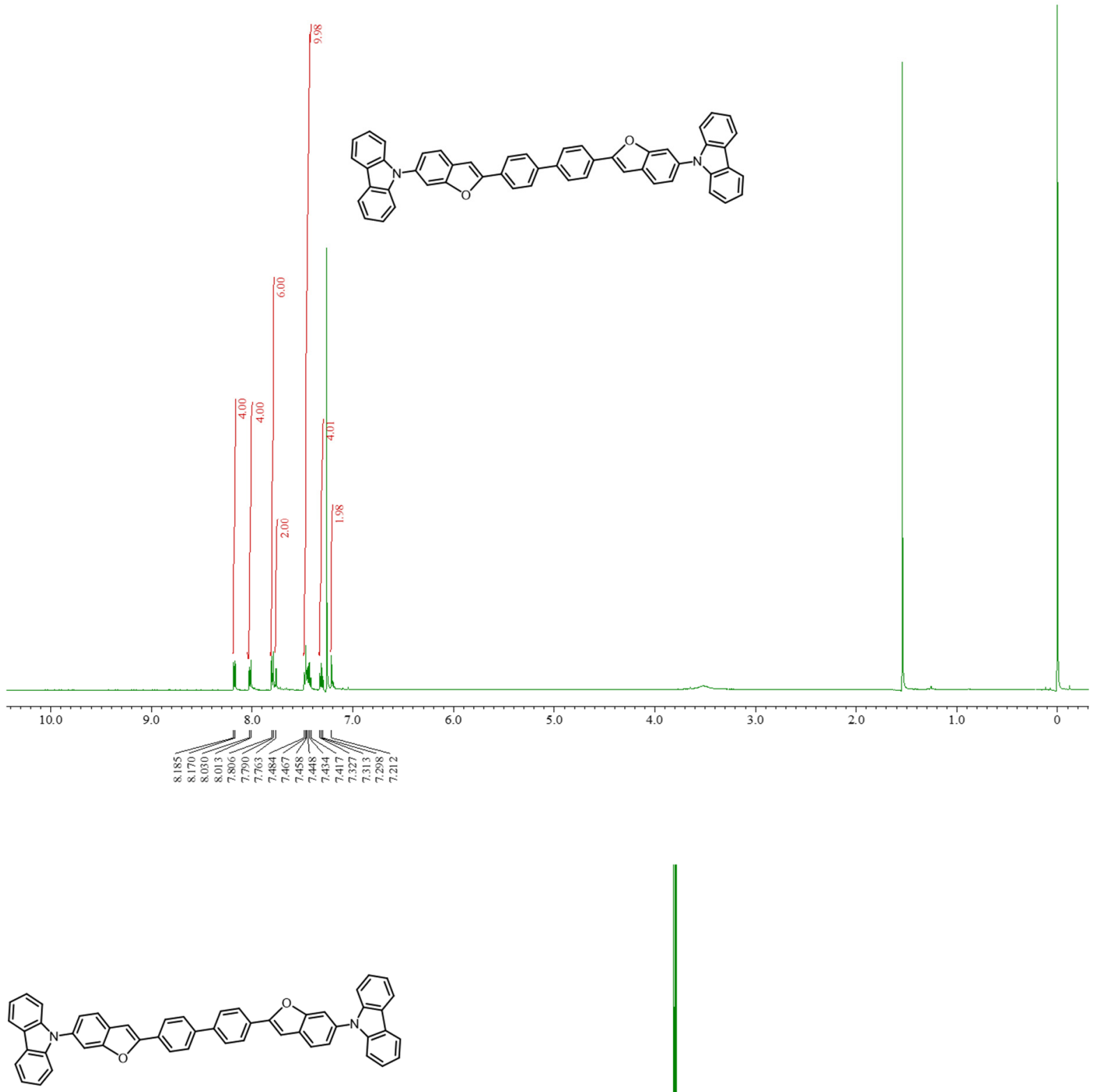

25 

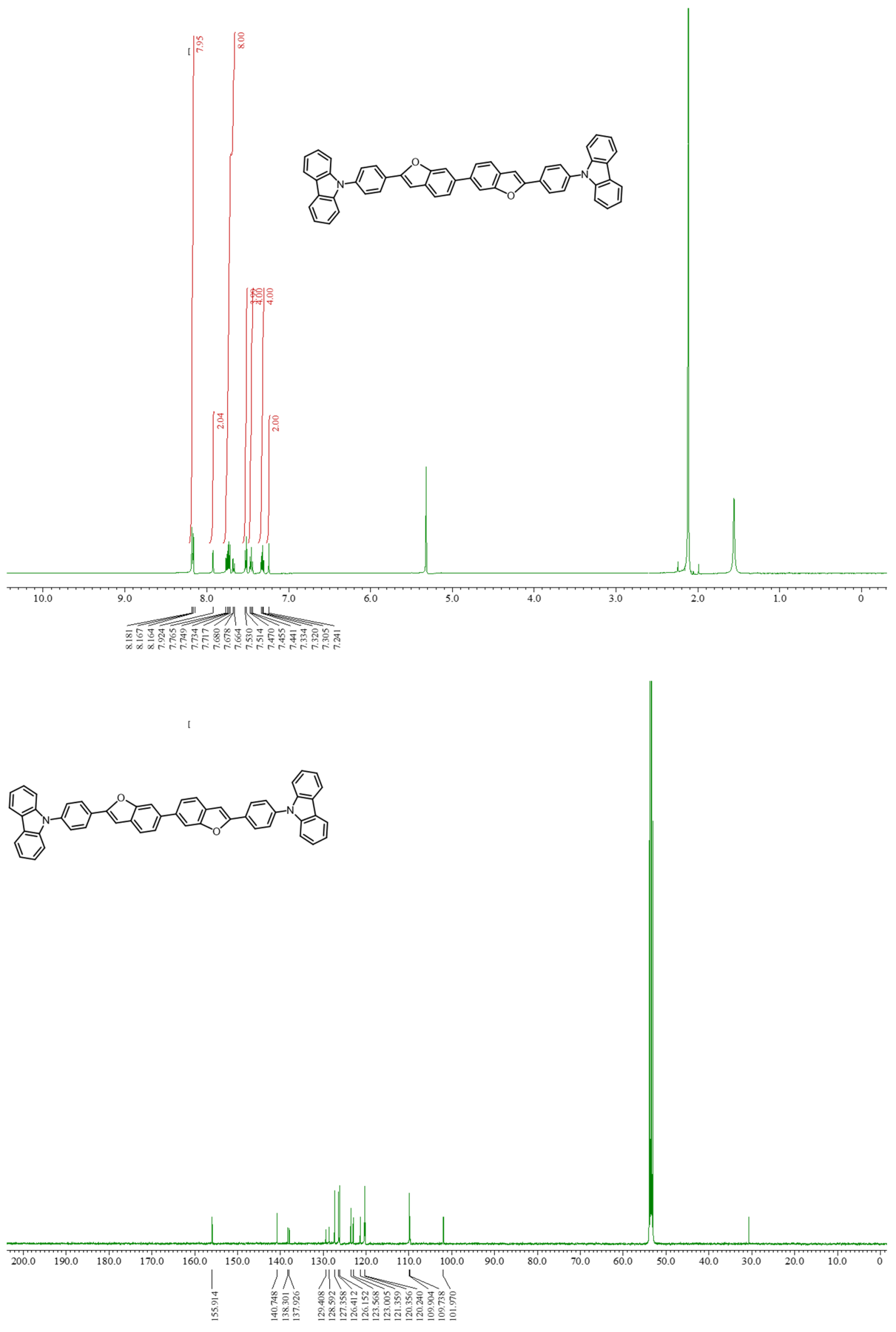

26 


\section{Supplementary References}

(S1) Sun, N.; Huang, P.; Wang, Y.; Mo, W.; Hu, B.; Shen, Z.; Hu, X. Zeolite-Catalyzed Synthesis of 2,3-Unsubstituted Benzo $[b]$ furans via the Intramolecular Cyclization of 2-Aryloxyacetaldehyde Acetals. Tetrahedron, 2015, 71, 48354841.

(S2) Wang, Y.; Chen, F.; Di, H.; Xu, Y.; Xiao, Q.; Wang, X.; Wei, H.; Lu, Y.; Zhang, L.; Zhu, J.; Sheng, C.; Lan, L.; Li, J. Discovery of Potent Benzofuran-Derived Diapophytoene Desaturase (CrtN) Inhibitors with Enhanced Oral Bioavailability for the Treatment of Methicillin-Resistant Staphylococcus aureus (MRSA) Infections. J. Med. Chem., 2016, 59, 3215-3230.

(S3) Gaussian 16, Revision C.01, Frisch, M. J.; Trucks, G. W.; Schlegel, H. B.; Scuseria, G. E.; Robb, M. A.; Cheeseman, J. R.; Scalmani, G.; Barone, V.; Petersson, G. A.; Nakatsuji, H.; Li, X.; Caricato, M.; Marenich, A. V.; Bloino, J.; Janesko, B. G.; Gomperts, R.; Mennucci, B.; Hratchian, H. P.; Ortiz, J. V.; Izmaylov, A. F.; Sonnenberg, J. L.; Williams-Young, D.; Ding, F.; Lipparini, F.; Egidi, F.; Goings, J.; Peng, B.; Petrone, A.; Henderson, T.; Ranasinghe, D.; Zakrzewski, V. G.; Gao, J.; Rega, N.; Zheng, G.; Liang, W.; Hada, M.; Ehara, M.; Toyota, K.; Fukuda, R.; Hasegawa, J.; Ishida, M.; Nakajima, T.; Honda, Y.; Kitao, O.; Nakai, H.; Vreven, T.; Throssell, K.; Montgomery, J. A., Jr.; Peralta, J. E.; Ogliaro, F.; Bearpark, M. J.; Heyd, J. J.; Brothers, E. N.; Kudin, K. N.; Staroverov, V. N.; Keith, T. A.; Kobayashi, R.; Normand, J.; Raghavachari, K.; Rendell, A. P.; Burant, J. C.; Iyengar, S. S.; Tomasi, J.; Cossi, M.; Millam, J. M.; Klene, M.; Adamo, C.; Cammi, R.; Ochterski, J. W.; Martin, R. L.; Morokuma, K.; Farkas, O.; Foresman, J. B.; Fox, D. J. Gaussian, Inc., Wallingford CT, 2016.

(S4) Yokoyama, D.; Sakaguchi, A.; Suzuki, M.; Adachi, C. Horizontal Orientation of Linear-Shaped Organic Molecules Having Bulky Substituents in Neat and Doped Vacuum-Deposited Amorphous Films. Org. Electron. 2009, 10, 127-137.

(S5) Mamada, M.; Fukunaga, T.; Bencheikh, F.; Sandanayaka, A. S. D.; Adachi, C. Low Amplified Spontaneous Emission Threshold from Organic Dyes Based on Bis-stilbene. Adv. Funct. Mater., 2018, 28, 1802130.

(S6) Nakanotani, H.; Adachi, C.; Watanabe, S.; Katoh, R. Spectrally Narrow Emission from Organic Films under Continuous-Wave Excitation. Appl. Phys. Lett. 2007, 90, 231109.

(S7) Forget, S; Chénais, S. Organic Solid-State Lasers, Springer-Verlag: Berlin, 2013. 